\title{
Yonjung High-Speed Railway Bridge Assessment Using Output-Only Structural Health Monitoring Measurements under Train Speed Changing
}

\author{
Mosbeh R. Kaloop, ${ }^{1,2,3}$ Jong Wan Hu, ${ }^{1,2}$ and Mohamed A. Sayed ${ }^{4}$ \\ ${ }^{1}$ Department of Civil and Environmental Engineering, Incheon National University, Incheon, Republic of Korea \\ ${ }^{2}$ Incheon Disaster Prevention Research Center, Incheon National University, Incheon, Republic of Korea \\ ${ }^{3}$ Department of Public Works and Civil Engineering, Mansoura University, Mansoura, Egypt \\ ${ }^{4}$ National Research Institute of Astronomy and Geophysics, Cairo, Egypt \\ Correspondence should be addressed to Jong Wan Hu; jongp24@incheon.ac.kr
}

Received 18 May 2016; Accepted 12 October 2016

Academic Editor: Guiyun Tian

Copyright ( 2016 Mosbeh R. Kaloop et al. This is an open access article distributed under the Creative Commons Attribution License, which permits unrestricted use, distribution, and reproduction in any medium, provided the original work is properly cited.

\begin{abstract}
Yonjung Bridge is a hybrid multispan bridge that is designed to transport high-speed trains (HEMU-430X) with maximum operating speed of $430 \mathrm{~km} / \mathrm{h}$. The bridge consists of simply supported prestressed concrete (PSC) and composite steel girders to carry double railway tracks. The structural health monitoring system (SHM) is designed and installed to investigate and assess the performance of the bridge in terms of acceleration and deformation measurements under different speeds of the passing train. The SHM measurements are investigated in both time and frequency domains; in addition, several identification models are examined to assess the performance of the bridge. The drawn conclusions show that the maximum deflection and acceleration of the bridge are within the design limits that are specified by the Korean and European codes. The parameters evaluation of the model identification depicts the quasistatic and dynamic deformations of PSC and steel girders to be different and less correlated when higher speeds of the passing trains are considered. Finally, the variation of the frequency content of the dynamic deformations of the girders is negligible when high speeds are considered.
\end{abstract}

\section{Introduction}

The Republic of Korea (South Korea) launched the Korea Train eXpress (KTX) in 2004 and High-Speed Electric Multiple Unit (HEMU-430X) in 2013, becoming the fifth nation to launch high-speed rail service $[1,2]$. The top design and operation speed for KTX is up to $350 \mathrm{~km} / \mathrm{h}$ and $305 \mathrm{~km} / \mathrm{h}$, respectively, while the design and operation speed for HEMU- $430 \mathrm{X}$ is up to $430 \mathrm{~km} / \mathrm{h}$ and $370 \mathrm{~km} / \mathrm{h}$, respectively. South Korea has developed its high-speed railway infrastructure successive phases, and the total length of the railway is $412 \mathrm{~km}$, of which $112 \mathrm{~km}(27 \%)$ consist of elevated viaduct and station structures and bridges [2]. Figure 1 illustrates the high-speed railway routes in South Korea.

In 2012, KTX trains carried nearly 53 million passengers, compared with the Southwest Airlines' 112 million enplanements for fiscal year 2012 [1]. Therefore, the performance assessment of the bridges that carry high-speed trains using various structural health monitoring systems is vital. Furthermore, more information can be found in $[2,3]$ for high-speed trains in South Korea. Kim et al. [4] have summarized most of the railway bridges along the high-speed railway construction in South Korea. Most of these highspeed railway bridges are double-span continuous prestressed reinforced concrete (PSC) box girder bridges with $40 \mathrm{~m}$ span, or single-span steel plate girder bridges with $40 \mathrm{~m}$ to $50 \mathrm{~m}$ span. The PSC box girder bridges are relatively dominant because there is a general consensus that concrete bridges are superior to steel bridges in terms of vibration and noise [4]. Furthermore, Kim et al. [4] have concluded that the dynamic performance of steel and concrete bridges has shown eligible differences for low and medium speeds up to $300 \mathrm{~km} / \mathrm{h}$. The 


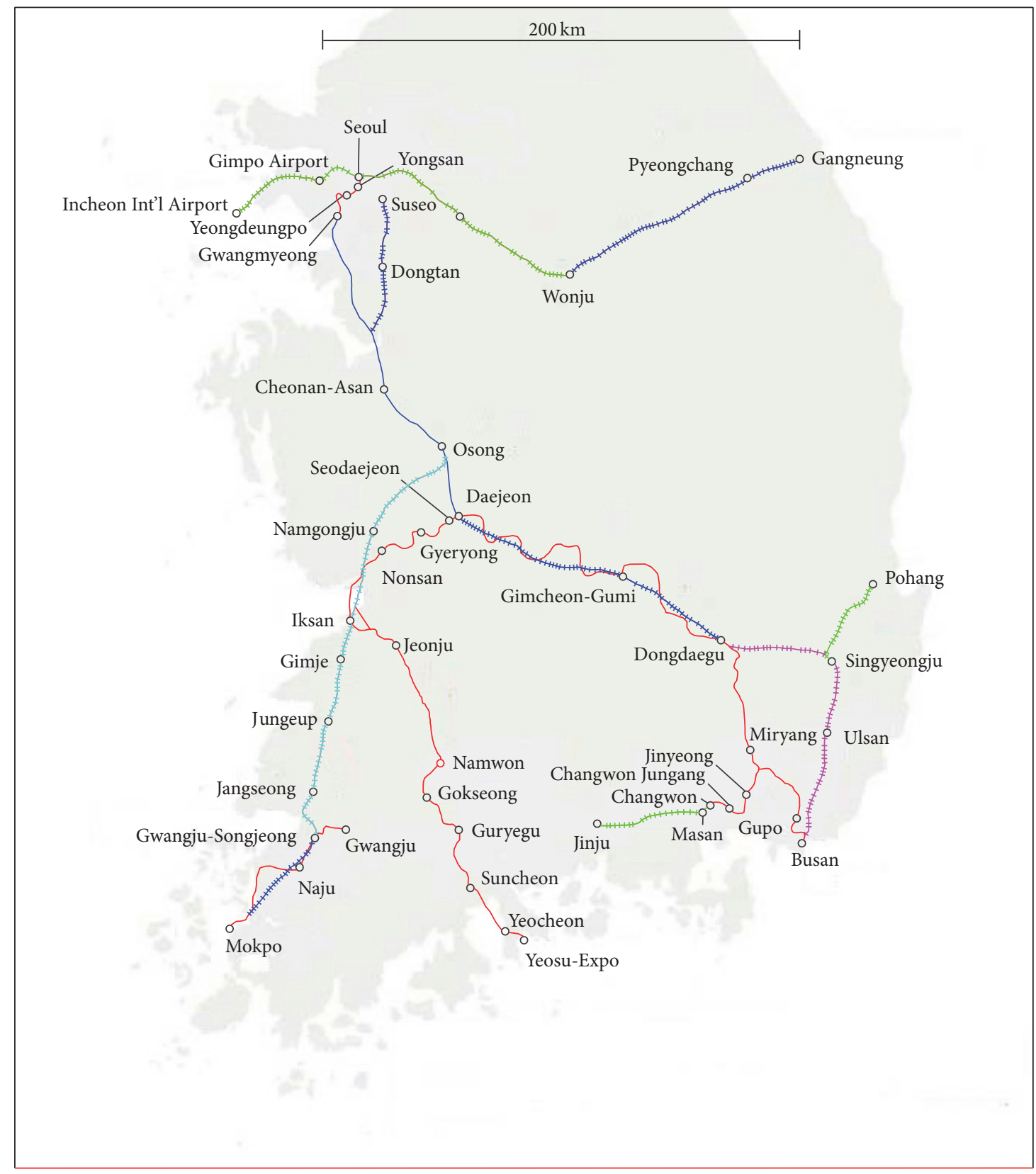

Railway type

$\begin{array}{ll}\text { - Core express 2004 } & \text { - Core express 2017 } \\ \text { Core express 2010 } & \text { Blended } \\ \text { Core express 2015 } & \text { - Under development }\end{array}$

FIGURE 1: Routes used and strategy plan railway for the high-speed trains in South Korea [1].

different design criteria for the high-speed railway bridges are concluded in Yan et al. [5] and Yoon et al. [6].

SHM is used to detect the behavior and performance of structures based on designing a reliable measurement system. The main purposes of the recorded measurements are assessing, evaluating, and predicting the performance of the structures under consideration in time and frequency domains. To assess the dynamic performance of different structures, the acceleration and displacement are common measurements that can be investigated. Many studies have conducted SHM techniques for the high-speed railway bridges. Previous studies and their concluded results are briefly introduced in the following sections.

Both theoretical and experimental studies have been continuously carried out on PSC box girder bridges, which account for the majority of the bridges along the high-speed 
railway system [4]. Ding et al. [7, 8] have applied different SHM systems that introduced various sensors for data and measurements collection. Furthermore, an evaluation system of the safety of the Nanjing DaShengGuan Bridge in China has been designed for the real-time condition assessment. In addition, the results revealed the effectiveness of the proposed SHM system in detecting the bridge's abnormal behaviors under the varying environmental conditions such as highspeed trains and environmental temperature. Kaloop et al. [9] have investigated and assessed Kaya Bridge that is a composite steel box girder bridge located in South Korea using a nondestructive monitoring system. The time and frequency domains for the recorded acceleration and strain measurements were utilized. The parametric and nonparametric models for accelerations and strain measurements were applied to predict the performance of the bridge. The results have shown that the static behavior is increased when train speed increases. The experimental and statistical tests for the strain measurements for the railways bridges are presented in [10, 11]. Ye et al. [10] have concluded that the life assessment of steel bridges using field monitoring data from an SHM system can be proposed, which in turn helps bridge management authority and engineers to make decisions in prioritizing inspection maintenance activities. Furthermore, the previous simulation studies have presented the safety design of high-speed trains and bridges as presented in Alves et al. [12], Martínez-Rodrigo et al. [13], and Rocha et al. [14].

In this paper, the quasistatic and dynamic characteristic of the Yonjung Bridge deformations is investigated. The performance assessment of two types of girders, that is, prestressed concrete and composite steel box girders of the bridge, is conducted. Moreover, the performance evaluation is considered including the identification model parameters and frequency content analysis for the quasistatic and dynamic deformations of the girders. Comparing the various deformation results under different speeds of two types of trains (HEMU and KTX) is investigated. In addition, the results are compared with the standard dynamic behavior requirements set by Eurocode and Korean High-Speed Railway. Finally, through interpretative analysis, a quantitative comparison between the prestressed concrete and steel girder is achieved.

\section{Yonjung Bridge Description}

The Yonjung Bridge is a multispan hybrid bridge constructed in South Korea. It connects Iksan and Jungeup cities. The bridge consists of several PSC box girders with various spans $(25 \mathrm{~m}$ and $40 \mathrm{~m})$ and a composite steel box girder with span $50 \mathrm{~m}$ as illustrated in Figure 2. The bridge is constructed for the Honam High-Speed Railway in South Korea. The bridge is designed to carry the KTX train and the new developed highspeed train (HEMU-430X) that has a top speed of $430 \mathrm{~km} / \mathrm{h}$. However, the Korean railway design code gives guidelines below $350 \mathrm{~km} / \mathrm{h}$ [15]. The axial spacing and loads of the wheels of the KTX-2 and the HEMU-430X high-speed trains are described in Figure 3. The HEMU-430X train consists of 6 railcars, while the KTX-2 train consists of 10 railcars. In this study, the PSC girder of $40 \mathrm{~m}$ span and the composite steel girder of span $50 \mathrm{~m}$ are to be investigated under the two types of aforementioned high-speed trains.

\section{Structural Health Monitoring Design and Setup}

Various sensors are applied to detect the static and dynamic deformations of the two girders of the bridge. Accelerometers denoted as (A), LVDT sensors, and ring gauges denoted as (R) are installed at different locations of the two girders. LVDT (CDP-10) strain transducers are used. The ring gauge (OU30 ) with capacity of $30 \mathrm{~mm}$ was attached to the strain gauge to detect the direct displacement of the girder. The installed sensors in the PSC girder and the composite steel girder are depicted in Figure 4. Two accelerometers are installed beneath the two railway tracks at the midspan of the girder. In addition, an LVDT sensor and a ring gauge are installed at the bottom flange of the girder as shown in Figure 4. The previous sensors are designed to establish a compatible SHM system with a minimum number of sensors to monitor the key parameters. In addition, the structural parameters to be monitored in this bridge were selected and chosen based on the previous bridges analyses in South Korea [4, 6 , 9]. Moreover, the SHM design also considered selecting the sensors that are appropriate for measuring the required physical quantities and parameters.

\section{Test Evaluation and Assessment}

The field measurement evaluation of the Yonjung Bridge is conducted to assess the static and dynamic performance of the bridge under the high-speed train passage. Two spans of the bridge, that is, PSC box girder ( $40 \mathrm{~m}$ span) and steel composite girder (50 $\mathrm{m}$ span), are evaluated. A set of experimental tests were performed during the operation of KTX and HEMU high-speed trains, and a number of accelerometers, LVDTs, and ring-type displacement transducer are utilized for measurement of the two main responses of the bridge (vertical acceleration and deflection). The time and frequency domains are analyzed and presented in this section. In addition, the Eurocode [16] and the specification of the Korean Rail Network Authority [2,17] are used to evaluate the traffic safety and ride comfort criteria.

4.1. Measurement Analysis. The deflection and acceleration measurements for two train types KTX with speed $169 \mathrm{~km} / \mathrm{h}$ and HEMU with speed $399 \mathrm{~km} / \mathrm{h}$ are shown in Figure 5. The time window of the different measurements is selected based on the effective train passage time. The measurements for the LVDTs and ring-type sensors show that the measurement accuracy for the LVDTs is higher, while the standard deviation for the LVDTs and ring-type sensors are 0.088 and $0.123 \mathrm{~mm}$ for the PSC girder and 0.278 and $0.385 \mathrm{~mm}$ for the steel girder during KTX passage, respectively.

From Figure 5, it can be seen that the PSC girder produces higher acceleration than the steel girder, while the deflection of the steel girder is higher. The previous results may be due to 


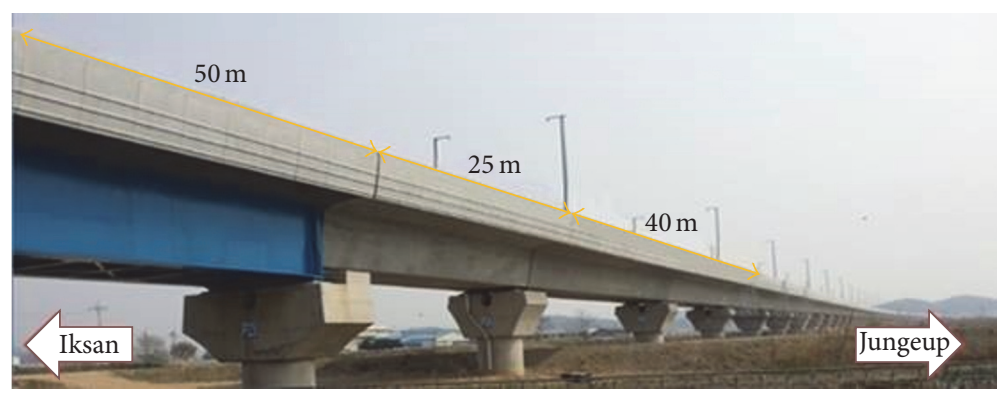

FIGURE 2: PSC and steel girders of Yonjung Bridge.

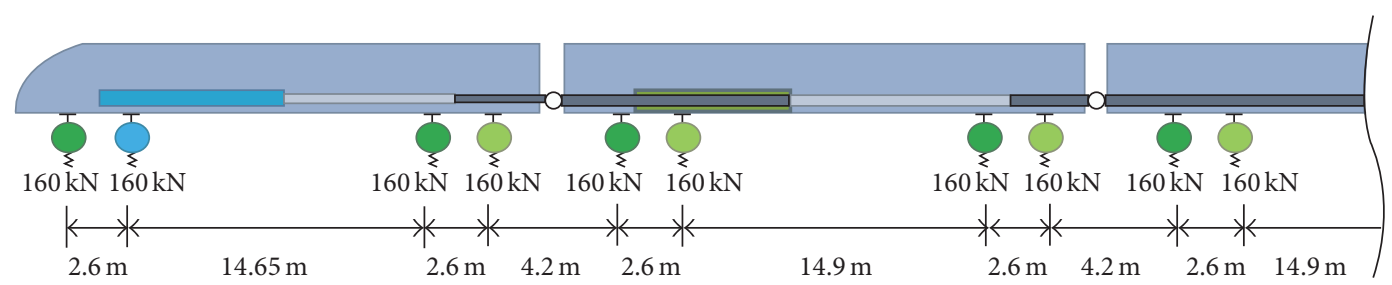

(a)

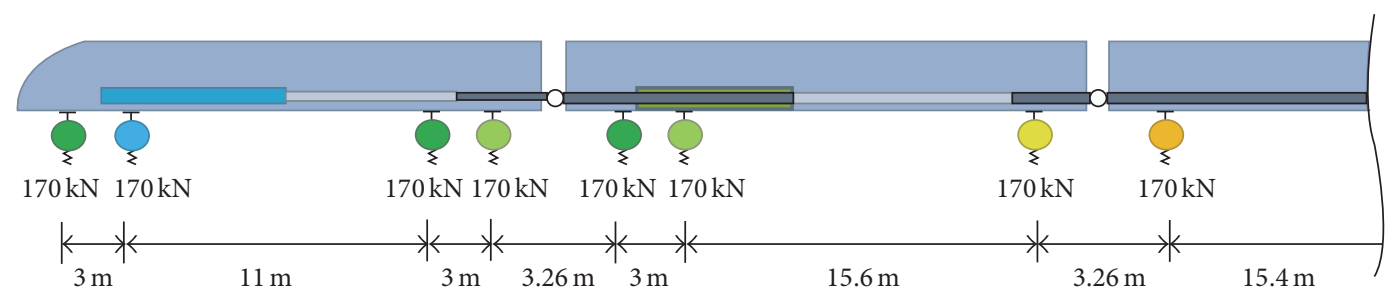

(b)

FIgURE 3: Axial spacing and loads of HEMU-430X train (a) and KTX-2 train (b).

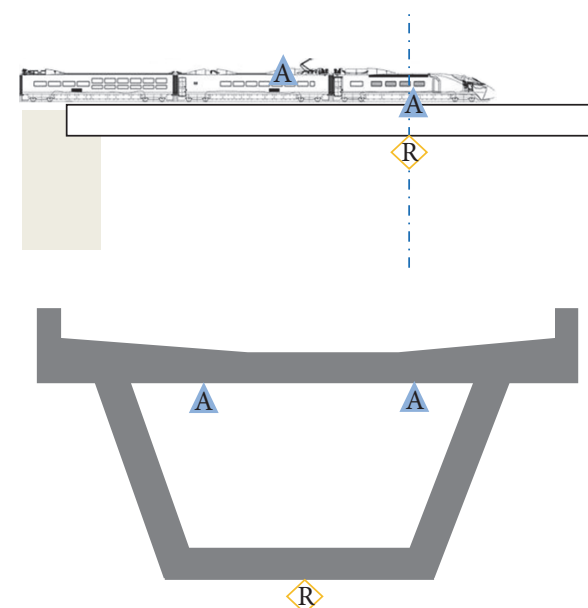

(a) PSC box girder

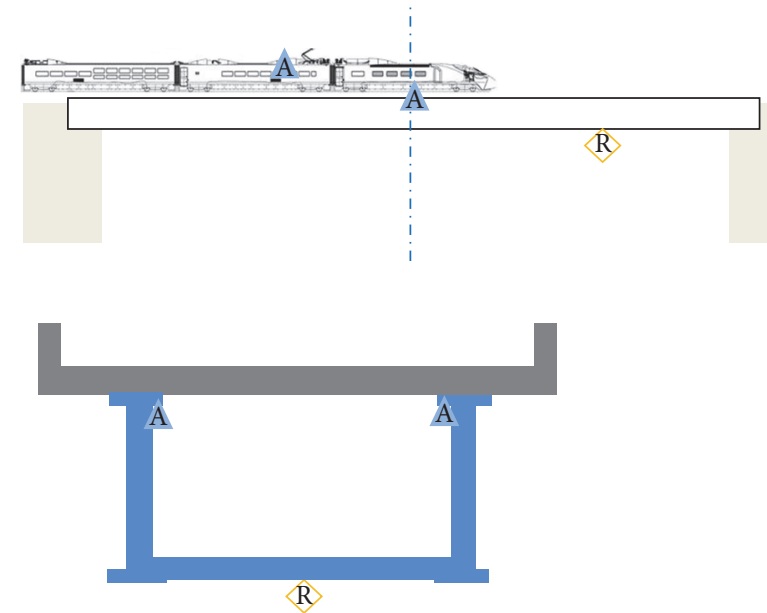

(b) Composite steel box girder

Figure 4: Sensors types and location at the different types of girders. 

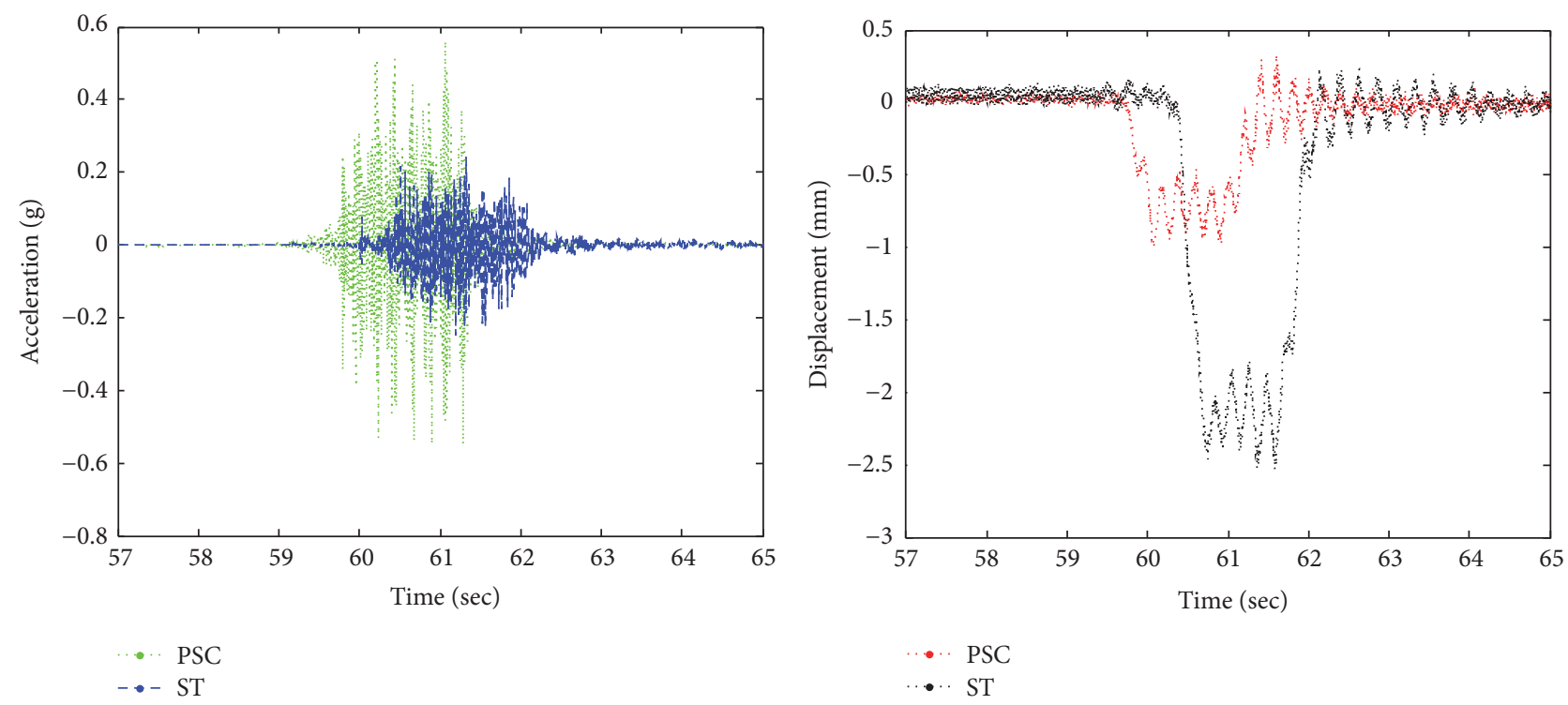

(a)
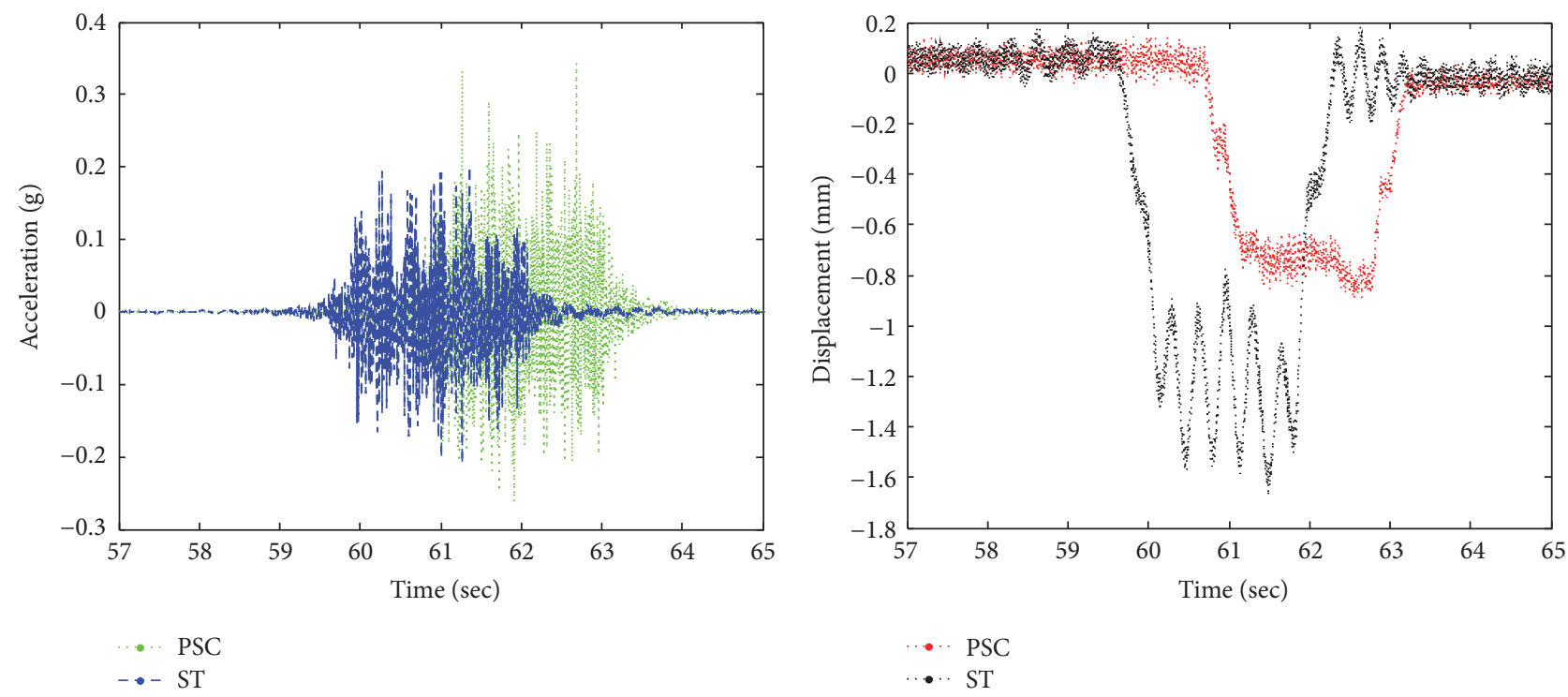

(b)

FIgURE 5: Vertical acceleration and deflection for the bridge girders for the (a) KTX (169 km/h) and (b) HEMU (399 km/h).

the higher stiffness and rigidity of the cross section of the PSC girder compared with the steel girder and due to the longer span of the steel girder. In addition, Table 1 illustrates the statistical measurements of the acceleration and deflection with different trains speeds. The table considers different speed for the trains, and it considers the train passage in the two directions separately, that is, passage direction (Pas.) and opposite direction (Ops.). In addition, the deflection is measured at (0.33) and (0.5), the length of the steel girder, while it is measured only at the midspan (0.5) for the PSC girder.

The variations of maximum passage direction acceleration and midspan deflection are shown by $50 \%$ and $68 \%$, respectively, between PSC and steel girders, as shown in Table 1, for the KTX trains. In addition, it can be shown that the maximum variation for the deflection of HEMU is 55\%, while the acceleration is about $39 \%$.

The acceleration and deflection of the PSC and steel girders decrease when increasing the train speed, whereas the dynamic wheel weight decreases during the upward movement. Furthermore, the difference between the maximum acceleration variations between passage and opposite direction for the PSC girder is shown to be higher than the variation for the steel girder. In addition, the maximum deflection under different train speeds is within the design criteria of the Korea Rail Network Authority. However, the results obtained from the maximum vertical acceleration differed significantly from the vertical deflection results. In other words, responses exceeding the criteria were observed in the PSC box girder with KTX trains. This is because the rigidity of PSC section 
TABLE 1: Maximum acceleration and deflection measurements.

\begin{tabular}{|c|c|c|c|c|c|c|c|c|}
\hline \multirow{3}{*}{$\begin{array}{l}\text { Train speed } \\
(\mathrm{km} / \mathrm{h})\end{array}$} & \multirow{3}{*}{ Direction } & \multicolumn{3}{|c|}{ PSC girder } & \multicolumn{4}{|c|}{ Steel girder } \\
\hline & & \multicolumn{2}{|c|}{ Peak Acc. (g) } & \multirow{2}{*}{$\begin{array}{l}\text { Def. }(\mathrm{mm}) \\
\quad 0.5 \mathrm{~L}\end{array}$} & \multicolumn{2}{|c|}{ Peak Acc. (g) } & \multicolumn{2}{|c|}{ Def. (mm) } \\
\hline & & Pas. & Ops. & & Pas. & Ops. & $0.33 L$ & $0.5 L$ \\
\hline KTX-165 & Iksan to Jungeup & 0.680 & 0.622 & 1.01 & 0.342 & 0.283 & 2.66 & 3.19 \\
\hline KTX-169 & Iksan to Jungeup & 0.562 & 0.560 & 1.00 & 0.279 & 0.248 & 2.53 & 3.04 \\
\hline HEMU-376 & Jungeup to Iksan & 0.257 & 0.164 & 1.06 & 0.193 & 0.134 & 1.84 & 2.21 \\
\hline HEMU-399 & Jungeup to Iksan & 0.320 & 0.223 & 0.90 & 0.211 & 0.126 & 1.68 & 2.02 \\
\hline HEMU-403 & Jungeup to Iksan & 0.343 & 0.260 & 0.90 & 0.209 & 0.091 & 1.67 & 2.00 \\
\hline
\end{tabular}

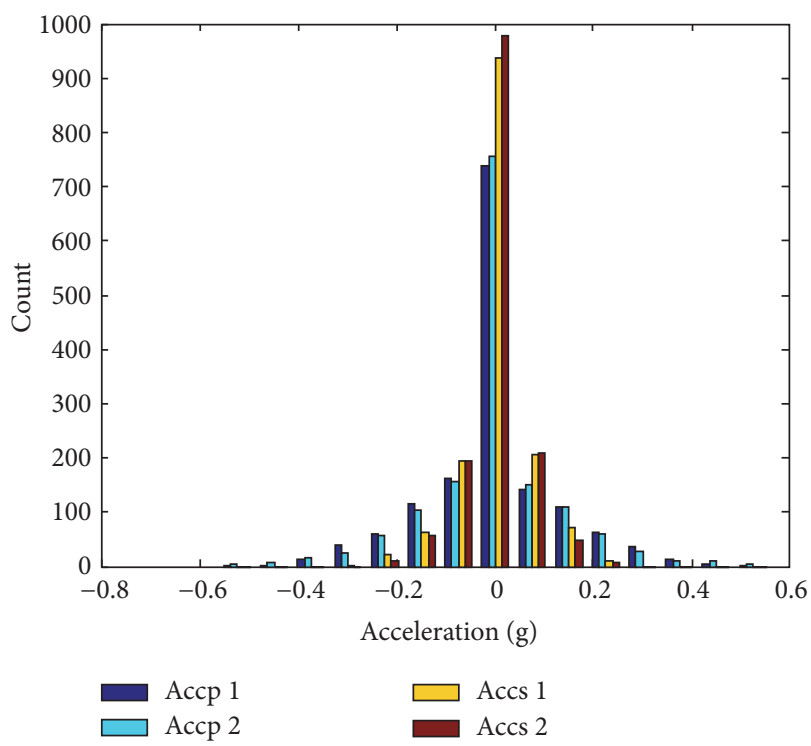

(a)

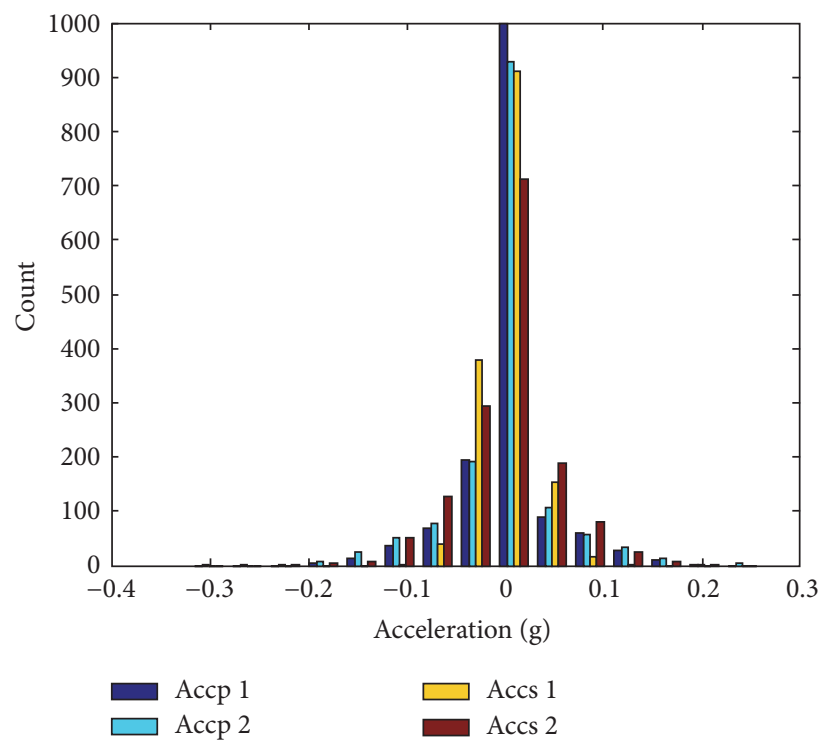

(b)

FIGURE 6: Histogram of measured acceleration (a) KTX and (b) HEMU.

of this type of bridge and the number of cars for the KTX train type or higher noise may have occurred. Therefore, Figure 6 presents the histogram of acceleration measurements for the KTX (169) and HEMU (399) to examine the errors effects. The maximum acceleration limit in Eurocode and Korea Rail Network Authority recommends the acceleration peak be less than $0.5 \mathrm{~g}$ [17]. Furthermore, the count number of the recorded acceleration exceeding $0.5 \mathrm{~g}$ is very small in case of KTX compared with HEMU case as illustrated in Figure 6. Moreover, it can be shown that no acceleration exceeded $0.5 \mathrm{~g}$ for HEMU train. The previous results indicate that the acceleration measurements contain noises and therefore errors that should be filtered prior to evaluation.

In addition, Figure 6 illustrates the distribution of the number of acceleration amplitude points for the two trains. The number of acceleration points that occurred more than 100 times and with amplitude between 0 and $\pm 0.2 \mathrm{~g}$ is increased when HEMU train is considered. It means that the high speeds influence the bridge vibration.

To assess the long-period (quasistatic) deformation, the signal filtration is applied to remove the measurement noises for the LVDT sensor. Figure 7 depicts the measurements and filters signals for the KTX-(169) and HEMU-(399). The lowpass moving average filter is applied to remove the dynamic deformations and noises $[9,18]$. In particular, based on the results of the analysis of numerous systematic measurements of oscillations of bridges, it was found that a simple low-pass filter (a moving average filter with a step of approximately $0.2 \mathrm{sec}$ ) permits separating measurements deflection into a long-period and a dynamic component.

The extracted long-period displacement after filtration at the deck level of the steel and PSC girders are very small. In addition, it can be seen that the deflection change for the PSC and steel decks by $9.6 \%$ and $33.3 \%$, respectively, due to train speed changes from 169 to $399 \mathrm{~km} / \mathrm{h}$, which implies that the deflection of the PSC girder is smaller than the steel girder.

4.2. Parameters of Models Identifications Analysis. Basically, the process of parameter identification is an optimization process with the aim of reducing a previously or futuritydefined objective function to a minimum. Although it is considered simple at the first glance, the procedure can become costly in terms of computational time when the set of variables increases. Herein, for the output models, the time 


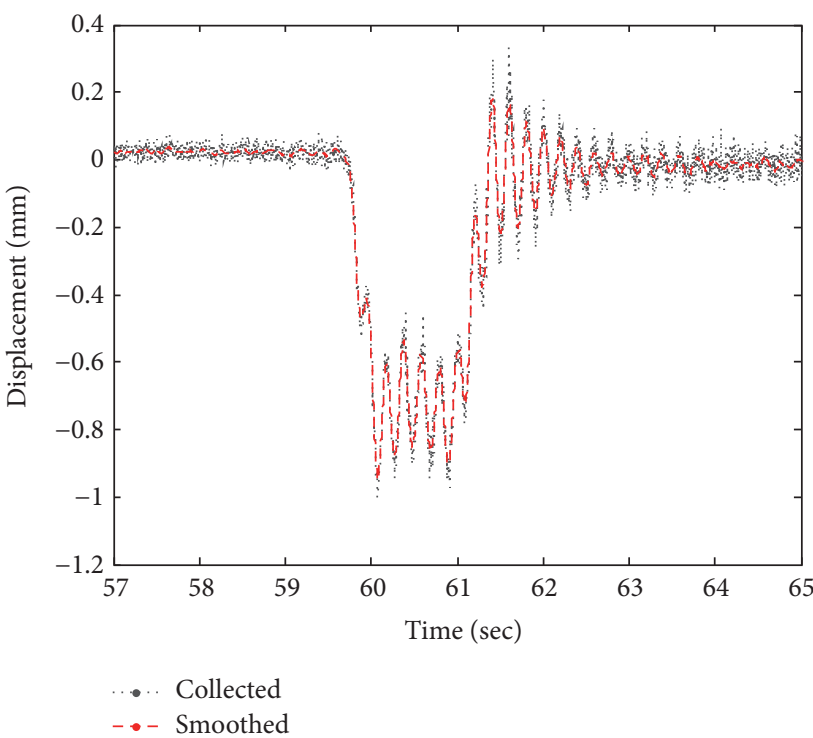

(a)

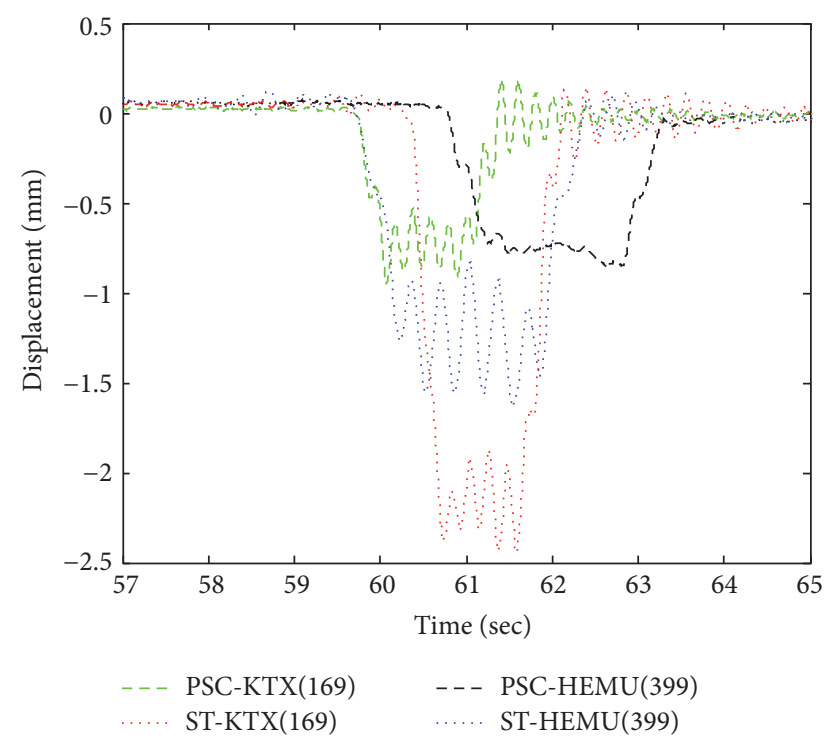

(b)

FIGURE 7: Static performance of bridge (a) moving average filter effective, (b) quasistatic deflection with train speeds.

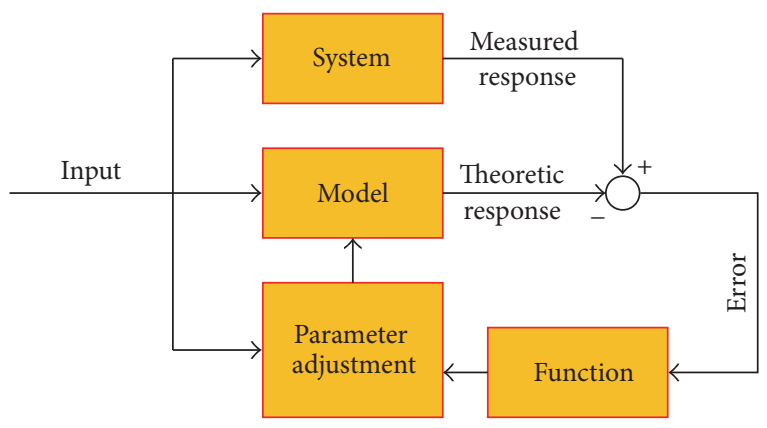

FIGURE 8: Parameter identification philosophy.

series model identification is one of the statistical analyses of measurements techniques. The model identification philosophy is presented in Figure 8. From this figure, it can be seen that the model parameter is used to detect the response of structures to check their behavior and safety. Therefore, in this part, we will focus on the model parameters for the selected model identification and check the performance of bridge and bridge materials based on the output-only measurements.

The model identification applications to evaluate structures are presented and discussed in Sohn et al. [19], Weng et al. [20], and Farrar and Worden [21]. Many models identifications are used to detect the performance and damage detection of structures in time and frequency domains [2225]. The most common and simple applied method is the method that introduces the correlation as a phenomenon that may be generated through lagged linear relations leading to proposing the autoregressive (AR), moving average (MA) and autoregressive moving average (ARMA) models $[19,22]$. In this study, the ARMA based on stochastic volatility generalized autoregressive conditionally heteroscedastic (GARCH) model is considered [22]. The ARMA nonlinear time series model is concerned with studying model of the form [22]

$$
x_{t}=f\left(x_{t-1}, x_{t-2}, \ldots, x_{t-p}\right)+g\left(e_{t}, e_{t-1}, \ldots, e_{t-q}\right) \text {, }
$$

where $f\left(x_{t-1}, x_{t-2}, \ldots, x_{t-p}\right)$ is a function of $p$ measurement variable $\left(x_{t}\right), g\left(e_{t}, e_{t-1}, \ldots, e_{t-q}\right)$ is a function of $q$ model random variables, and $e_{t}$ is white noise for the ARMA model. For each $t \Xi Z$, consider a random variable $e_{t} \sim N\left(0, \sigma^{2}\right)$; $e_{t}$ is normally distributed with mean zero and variance $\sigma^{2}$. The general conditional variance model for the conditional variance (Glosten, Jagannathan, and Runkle (GJR)) of the innovations with leverage terms is applied, as follows [22, 26]:

$$
\sigma_{t}^{2}=K+\sum_{i=1}^{S} G_{i} \sigma_{i-1}^{2}+\sum_{j=1}^{V} A_{j} e_{t-j}^{2}+\sum_{j=1}^{V} L_{j} S_{t-j} e_{t-j}^{2}
$$

where $K>0$, the $\operatorname{GARCH}(S, V)$ process for the $\operatorname{ARMA}(p, q)$ model, has a polynomial $G$ of order $S$, the autoregressive term, and a polynomial $A$ of order $V$, the moving average term; and the leverage coefficients $L$ apply to estimate using the maximum likelihood techniques; and $S_{t-1}=1$, if $e_{t-1}<0$, or 0 , if $e_{t-1} \geqslant 0$. However, to estimate the parameters of a model, the time series measurements are realizations of random variables with a known distribution but unknown parameters. The main objective of the maximum likelihood technique is to maximize the probability of observing the realizations considering a known parametric distribution with unknown parameters [26-28]. In GARCH, the variance is an autoregressive process around a long-term average variance rate; in addition, the $\operatorname{GARCH}(1,1)$ model assumes one lag period in the variance. For a GARCH model with normal 
distribution, the condition density function of prediction vector $\left(y_{t}\right)$ is $[27,28]$

$$
\xi\left(y_{t} \mid x_{t}, \theta\right)=\frac{1}{\sqrt{2 \pi \sigma_{t}^{2}}} \exp \left\{\frac{-e_{t}^{2}}{2 \sigma_{t}^{2}}\right\},
$$

where $\theta$ is vector of estimated parameters. Herein, using the maximum log-likelihood method to estimate the parameters in the GARCH model, the log-likelihood function of the normal distribution can be presented as follows [27]:

$$
\mathscr{L}_{N}(\theta)=\ln \prod_{t} \frac{1}{\sqrt{2 \pi \sigma_{t}^{2}}} \exp \left\{\frac{-e_{t}^{2}}{2 \sigma_{t}^{2}}\right\} .
$$

The parameters $\theta$ which fit the model best are obtained by minimizing the log-likelihood function [27]. However, the full set of parameters from the mean and variance equations are estimated.

Therefore, in this section, the ARMA model based on GARCH process will be applied to estimate the parameters for the filtered displacement and acceleration measurements for the PSC and steel girders during KTX and HEMU train passage. It should be mentioned that the estimation of parameters of ARMA model and GARCH process usually requires a more complicated iteration procedure. However, firstly the model parameters are defined to estimate the proper model parameters to be used. Therefore, two criteria are applied to define the best model parameters and order can be used. The first criterion to find a suitable model is to use the Akaike Information Criterion (AIC), where smaller AIC means better quality of models parameters numbers can be used. The AIC for model estimation can be calculated as follows $[22,26]$ :

$$
\begin{aligned}
\text { AIC }= & -2 \text { log-likelihood functions } \\
& +2 \text { numbers of parameters. }
\end{aligned}
$$

The second criterion is the autocorrelation function (AF) that is used to assess the models errors $\left(e_{t}\right)$. The lag $(m)$ autocorrelation is defined as follows [26]:

$$
\lambda(m)=\frac{1}{n} \sum_{t=1}^{n} e_{t-m} e_{t}
$$

The autocorrelation $\lambda(m)$ is zero when parameter model is nonzero. A large autocorrelation when parameter model is nonzero indicates that the residual is not zero-mean error. In real world applications, $\lambda(m)$ cannot be zero when $m$ is nonzero because of limited length of observation points. If the value of AC falls within $95 \%$ of the confidence interval, the $\mathrm{AC}$ value is insignificant and this value is considered to be equal to zero. Table 2 and Figure 9 illustrate the statistical results of the displacement and acceleration for the steel girder considering HEMU-399 train. The results are calculated considering $\operatorname{GRACH}(1,1)$ model.

From Table 2, it can be seen that the AIC for the displacement increases with the parameters of the model. In addition, the model $\operatorname{ARMA}(0,1)$ is believed to be the
TABLE 2: AIC for the displacement and acceleration measurements for the steel girder models.

\begin{tabular}{lcccccc}
\hline \multirow{2}{*}{ Model } & \multicolumn{6}{c}{ ARMA } \\
& $(0,1)$ & $(1,0)$ & $(1,1)$ & $(2,1)$ & $(1,2)$ & $(2,2)$ \\
\hline AIC-Disp & $-1.3 e 3$ & $-1.1 e 4$ & $-1.3 e 4$ & $-1.5 e 4$ & $-1.3 e 4$ & $-1.6 e 4$ \\
AIC-Acc & $-9.5 e 3$ & $-9.7 e 3$ & $-9.8 e 3$ & $-1.0 e 4$ & $-9.8 e 3$ & $-9.8 e 3$ \\
\hline
\end{tabular}

best model to use in this case. Moreover, the AF with 95\% confidence intervals of the residuals for the model $\operatorname{ARMA}(0,1)$ and $(1,1)$ shows that the residuals for the $(0,1)$ model remained in the boundaries of the $\mathrm{AF}$ confidence interval, while there was no loss of information in the description of the measurements data. Similar results are investigated for the acceleration measurements. However, it can be seen that the models in Table 2 can be used while the values of AIC are close values in the case of acceleration measurements. Furthermore, the AF with $95 \%$ confidence intervals of the residuals for the models $(0,1)$ and $(1,1)$ are significant also with 95\% interval. Furthermore, from the previous results, it can be concluded that the $\operatorname{ARMA}(0,1)$ model can be used to detect the bridge performance for the displacement and acceleration. In addition, the $\operatorname{GARCH}(1,1)$ and $\operatorname{GARCH}(1,2)$ and $(2,1)$ are evaluated and it is shown that the $\mathrm{AF}$ and $95 \%$ confidence intervals of the residuals for the two models are within the statistical confidence of acceleration measurements, as shown in Figure 10. Therefore, the $\operatorname{GARCH}(1,1)$ process model is considered in this study.

Therefore, the parameters of models using $\operatorname{ARMA}(0,1)$ $\operatorname{GARCH}(1,1)$ model for each train case are introduced in this section. The statistical test is applied to evaluate the parameters. The histogram of the model error with the probability density function of Gaussian distribution with the same mean value and a standard deviation for the displacement and acceleration of PSC girder when HEMU train is considered are presented in Figure 11. As mentioned previously, the displacement in Table 3 represents the deflection for the girder midspan, while the acceleration is recorded for the passage direction. In addition, the parameters $C$ and $M$ refer to the ARMA model, while the $K, G, A$, and $L$ parameters refer to the GRACH process as shown in (2). However, for the $\operatorname{ARMA}(0,1)-\operatorname{GARCH}(1,1)$ model, the parameter of set estimated from (4) reduced to $\theta=(C, M, K, G, A, L)$. Based on Figure 11, the estimated models parameters in Table 3 can be confirmed, while the model errors in the two cases can be described as a zero-mean, stationary, and ergodic Gaussian random process. Such a statement was confirmed also in the paper [29] and it was taken into consideration for the assessment of the models on the accuracy of the performance estimation.

Our first indication that the model is good is based on the $K$ value results, as the lower the $K$ parameter, the better the model [22]. From Table 3 , it can be seen that the $K$ value for the models in the cases of displacement and acceleration for the PSC and steel girders is very small and the statistical test is significant. In addition, it can be shown that the models for the steel girder with KTX or HEMU are better than PSC girder in the two output measurements. It means that the 

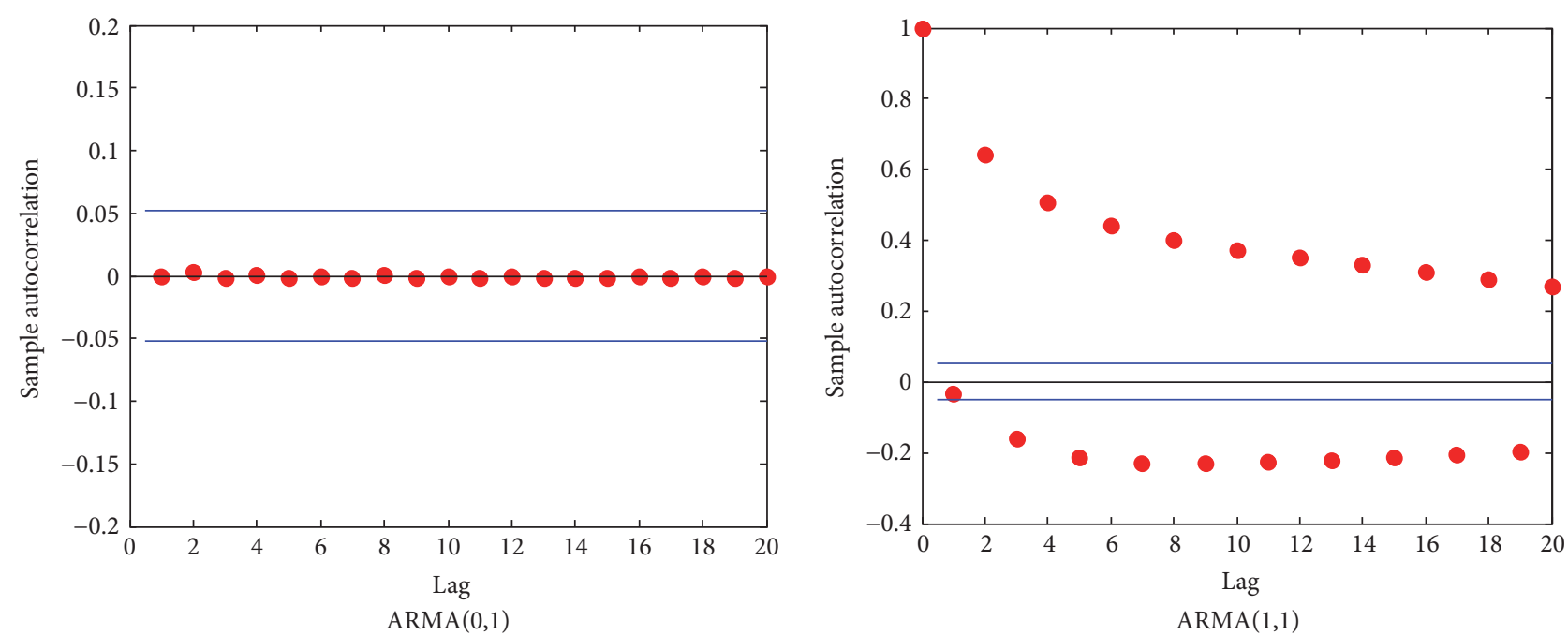

(a)
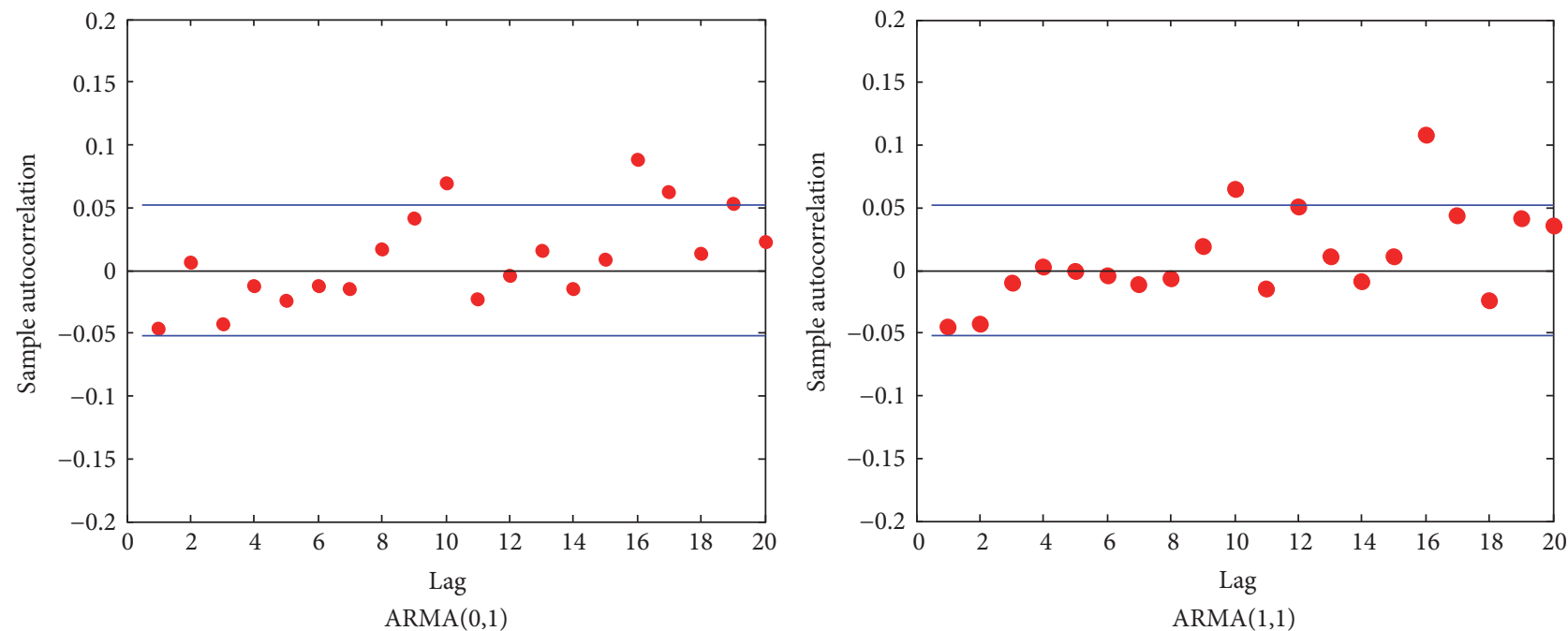

(b)

FIGURE 9: AF with 95\% confidence intervals of the residuals for the (a) displacement and (b) acceleration.

rigidity of PSC girders affects the model identification quality of bridge performance.

Moreover, the standard errors for the parameters are acceptable in the two cases of measurements and girders types. Furthermore, the $t$-statistical test for the ARMA model with displacement measurement is shown to be higher than that with acceleration measurements. It means that the ARMA parameters are more significant with acceleration measurements, while vice versa is shown with the variance parameters. That means that the displacement models are more significant with the variance of the measurements. Herein, it can be concluded that the model design for the performance of structures depends on two parameters that are the measurements and their variance. In the case of low variation, the measurements are more significant to design the model while with high variation measurements, such as displacements, the variance of measurements is more significant.
The displacement parameters changes between the two models of PSC and steel girders are shown to be 3.2, 12.6, and $3.2 \%$ for the $M, G$, and $A$ parameters, respectively, in the KTX case. In the case of HEMU, the changes between the two models are $14.8,100.0$, and $15.5 \%$ for the $M, G$, and A parameters, respectively. It means that the performance of two girders for the deflection measurements can be estimated by one model with low train speeds, while, in the case of acceleration measurements, it can be seen that the $M, G$, and $A$ parameters changes are 31.7, 3.6, and 59.9\% and 68.1, 13.8 , and $29.3 \%$ for the KTX and HEMU trains, respectively. It is noted that the parameters changes for the acceleration measurements are higher than those shown in displacement measurement; it means that the acceleration response for the each girder type under the two train loadings is different in terms of the dynamic deformations. Therefore, it can be concluded that the static performance of PSC and steel bridge deck are approximately equal in the case of low speeds, while 


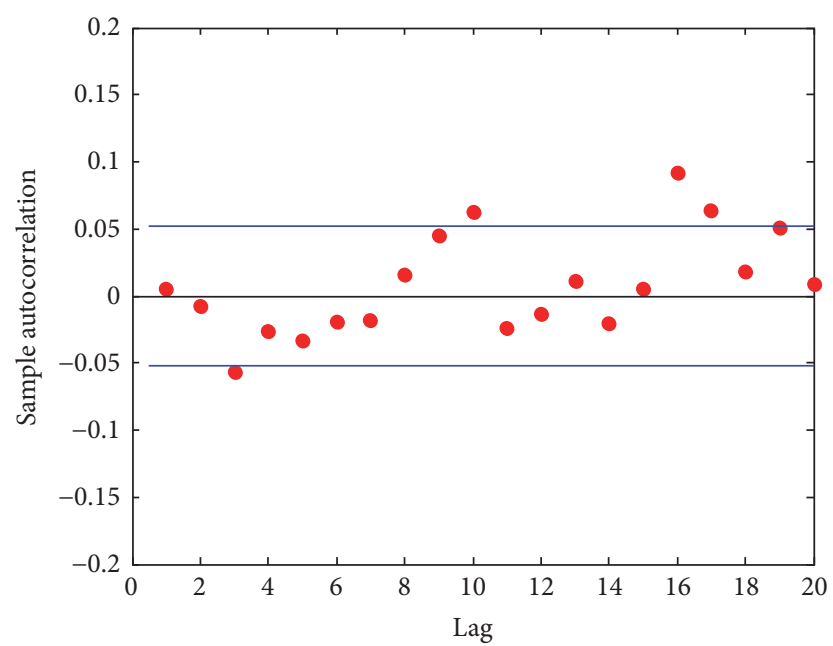

(a)

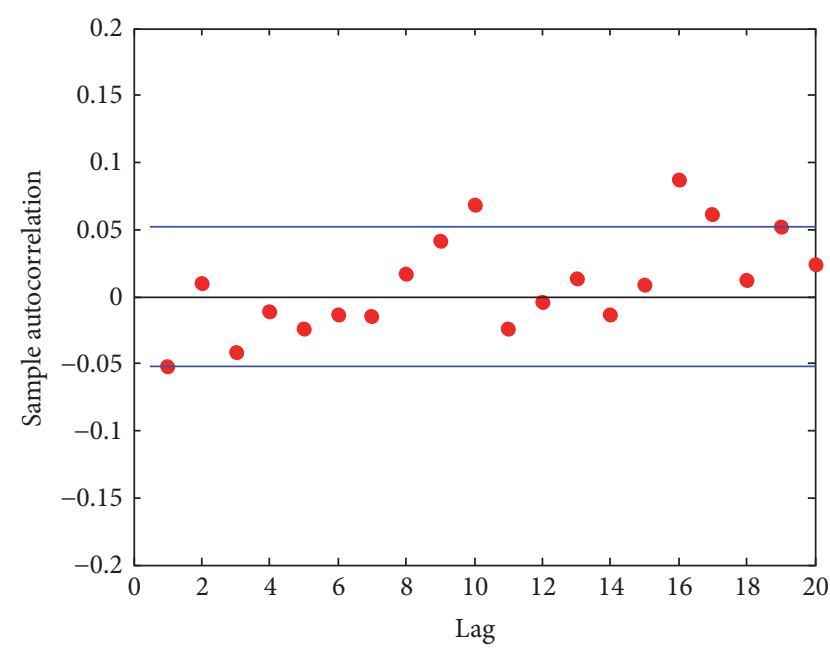

(b)

FIgURE 10: AF with 95\% confidence intervals of the residuals for the (a) $\operatorname{GARCH}(2,1)$ and (b) $\operatorname{GARCH}(1,2)$.

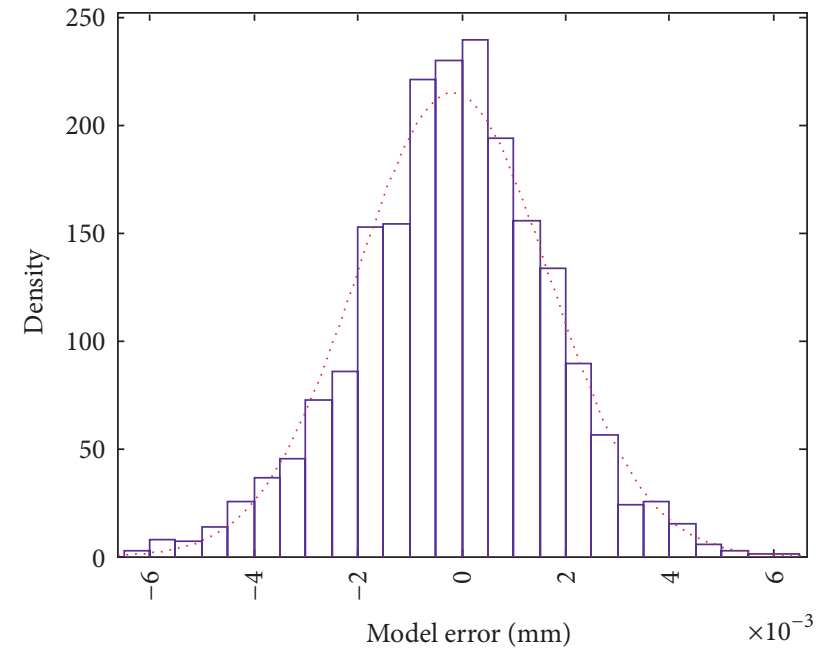

Disp-p

Gaussian

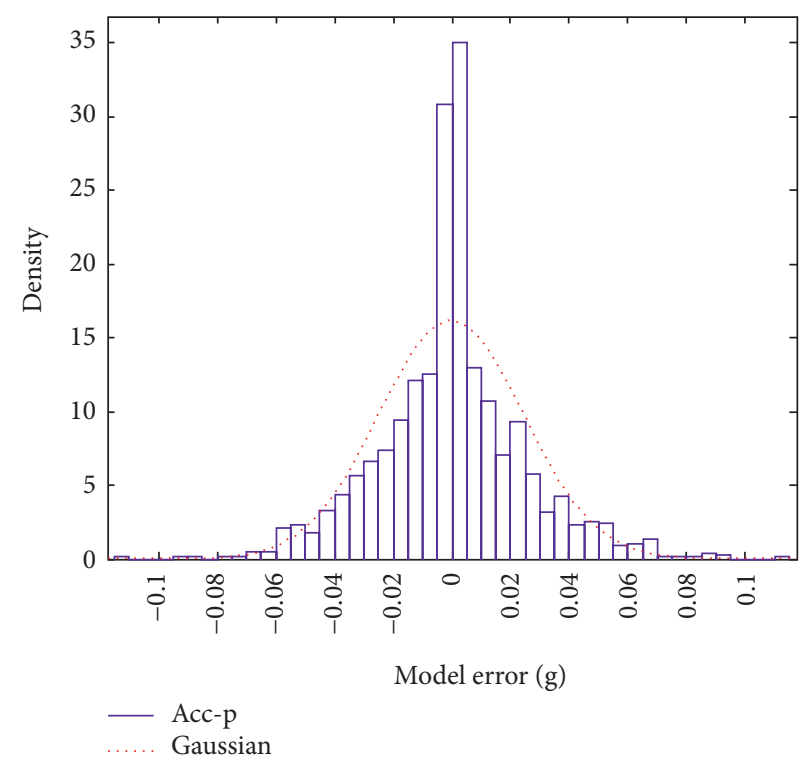

(b)

FIGURE 11: Comparison of the histogram of model error with the probability density function of Gaussian distribution with the same mean value and standard deviation for the displacement (a) and acceleration (b) considering HEMU.

the static and dynamic performance of two girders types are much different with higher speeds. Moreover, the $M, G$, and A parameters changes for the passage and opposite direction of acceleration measurements are 3.9, 8.9, and 6.2\% and 29.0, 1.8 , and $13.5 \%$ for the PSC and steel girders, respectively, for the HEMU train, which means that the rigidity of PSC girder affects the model identification parameters, and the torsion of steel girder is higher than the PSC girder.

\subsection{Quasistatic and Dynamic Frequencies Content Analysis.} The change of the frequency content is one of the mode shape analyses in the frequency domain of structures $[19,30]$. In this section, the frequency content is analyzed; the MATLAB periodogram tool is used to calculate the frequency and power spectrum density (PSD) contents. The filters calculations for the measurements are used in this section. Figure 12 illustrates the acceleration frequency content for the PSC and steel girders in the two cases for the KTX and HEMU.

The KTX dynamic frequency content shows that the frequency modes for the steel girder are 4.4, 36.6, 45.4, and $50.3 \mathrm{~Hz}$, while they are $4.9,31.7,36.1,45.4$, and $50.3 \mathrm{~Hz}$ for the PSC girder. The maximum PSD for the steel and PSC girders are $1.5 e-3$ and $6.0 e-3 \mathrm{~dB}$, respectively, for frequencies 36.6 and $45.4 \mathrm{~Hz}$, respectively. In addition, for the HEMU train, it can be seen that the frequency modes are 2.93, 8.3, 19.0, 43.5, 49.2, and $52.3 \mathrm{~Hz}$ and $4.4,8.3,29.3,43.5$, 
TABLE 3: Models parameters and evaluation for the displacement and acceleration measurements.

\begin{tabular}{|c|c|c|c|c|c|c|c|}
\hline \multirow{2}{*}{ Train } & \multirow{2}{*}{ Parameter } & \multicolumn{3}{|c|}{ PSC girder } & \multicolumn{3}{|c|}{ Steel girder } \\
\hline & & Value & St. error $(\%)$ & $t$-statistic & Value & St. error $(\%)$ & $t$-statistic \\
\hline \multicolumn{8}{|c|}{ Displacement models } \\
\hline \multirow{6}{*}{ KTX } & $C$ & -0.636 & 0.001 & -99.987 & 0.383 & $2.3 e-4$ & 86.547 \\
\hline & $M$ & 0.964 & 0.010 & 92.920 & 0.933 & 0.011 & 84.223 \\
\hline & K & $7.2 e-6$ & $4.6 e-6$ & 1.577 & $6.2 e-7$ & $2.2 e-7$ & 2.887 \\
\hline & $G$ & 0.293 & 0.097 & 3.023 & 0.256 & 0.055 & 4.655 \\
\hline & $A$ & 0.716 & 0.231 & 3.097 & 0.739 & 0.187 & 3.959 \\
\hline & $L$ & -0.019 & 0.250 & -0.078 & 0.009 & 0.231 & 0.037 \\
\hline \multirow{6}{*}{ HEMU } & $C$ & -0.004 & $2.0 e-4$ & -22.049 & -0.113 & 0.002 & -63.802 \\
\hline & $M$ & 0.846 & 0.015 & 55.562 & 0.971 & 0.010 & 100.448 \\
\hline & $K$ & $2.5 e-6$ & $3.2 e-7$ & 8.139 & $1.5 e-5$ & $1.1 e-5$ & 1.410 \\
\hline & $G$ & 0.000 & $3.7 e-4$ & 0.000 & 0.279 & 0.096 & 2.897 \\
\hline & $A$ & 0.867 & 0.206 & 4.202 & 0.733 & 0.227 & 3.226 \\
\hline & $L$ & 0.145 & 0.256 & 0.566 & -0.024 & 0.273 & -0.089 \\
\hline \multicolumn{8}{|c|}{ Acceleration models } \\
\hline \multirow{6}{*}{ KTX } & $C$ & $1.4 e-4$ & $4.7 e-4$ & 0.301 & $-1.1 e-4$ & $1.1 e-4$ & -0.991 \\
\hline & $M$ & 0.536 & 0.022 & 23.874 & 0.366 & 0.020 & 18.041 \\
\hline & K & $1.1 e-6$ & $5.1 e-7$ & 2.188 & $2.0 e-7$ & $3.5 e-8$ & 5.770 \\
\hline & $G$ & 0.814 & 0.012 & 67.968 & 0.785 & 0.009 & 86.207 \\
\hline & $A$ & 0.172 & 0.020 & 8.676 & 0.275 & 0.019 & 14.720 \\
\hline & $L$ & 0.028 & 0.027 & 1.008 & -0.121 & 0.018 & -6.818 \\
\hline \multirow{6}{*}{ HEMU } & $C$ & $2.2 e-4$ & $1.2 e-4$ & 1.888 & $9.8 e-5$ & $1.6 e-4$ & 0.599 \\
\hline & $M$ & 0.623 & 0.020 & 31.644 & 0.199 & 0.026 & 7.521 \\
\hline & K & $2.0 e-7$ & $5.2 e-8$ & 3.847 & $2.0 e-7$ & $6.5 e-8$ & 3.055 \\
\hline & $G$ & 0.744 & 0.015 & 48.710 & 0.847 & 0.013 & 65.742 \\
\hline & $A$ & 0.225 & 0.026 & 8.776 & 0.159 & 0.021 & 7.733 \\
\hline & $L$ & 0.062 & 0.037 & 1.659 & -0.013 & 0.025 & -0.516 \\
\hline
\end{tabular}
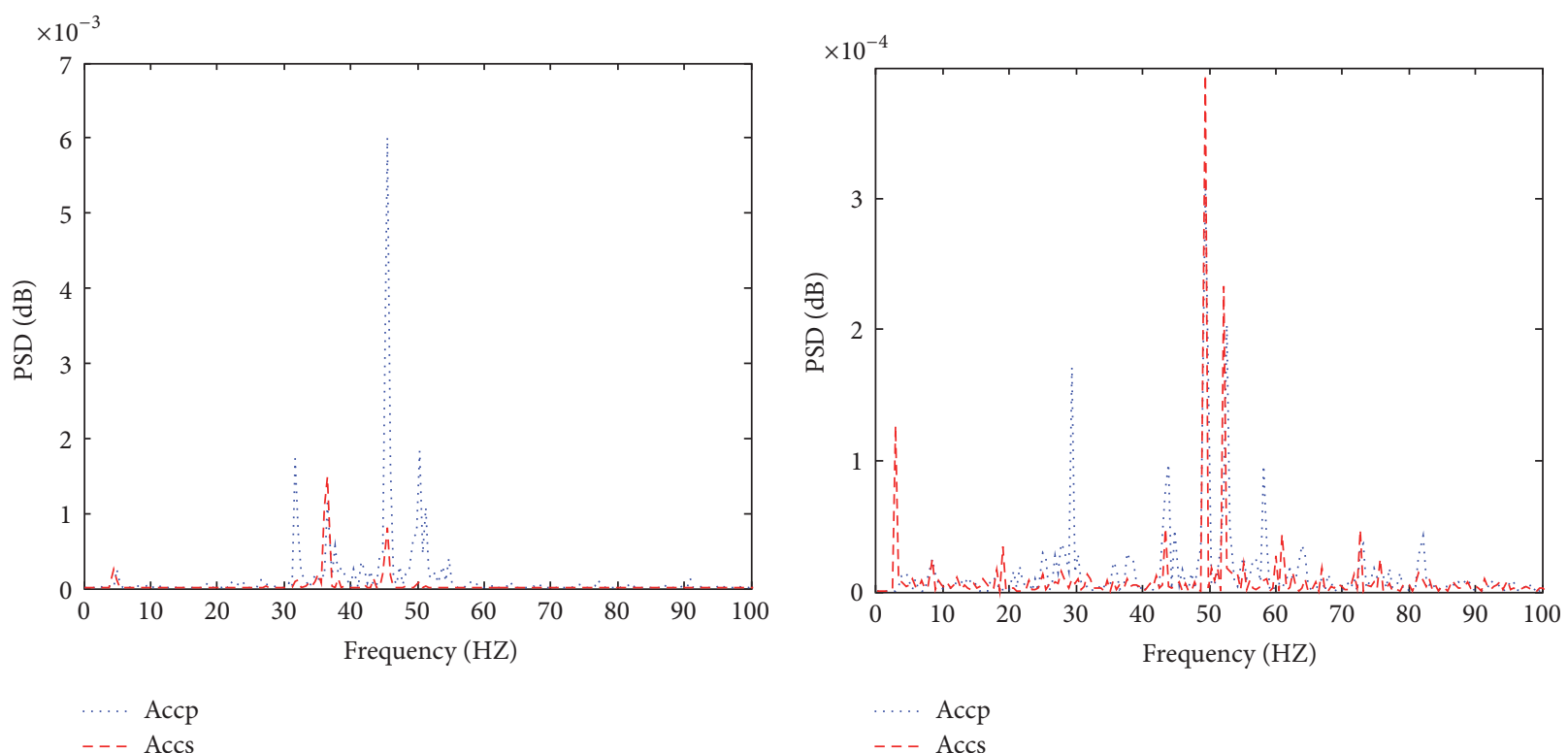

(a)

(b)

FIGURE 12: Acceleration frequency contents for the (a) KTX and (b) HEMU trains. 
49.2, and $52.7 \mathrm{~Hz}$ for the steel and PSC girders, respectively. Moreover, it can be observed that the maximum PSD for the dominant frequency for the steel and PSC girders are $3.9 e-4$ and $3.1 e-4 \mathrm{~dB}$, respectively. Furthermore, it can be seen that the dominant frequency for each girder with HEMU train is $49.2 \mathrm{~Hz}$. However, it can be concluded that the dominant frequency change for the PSC girder is much smaller than steel girder, because of the rigidity of PSC girder. In addition, it can be noted that the frequency content of the dynamic deformations changes negligibly when increasing the train speed; however, with low speeds, the frequency content changes significantly. Moreover, the PSD values for the HEMU trains are shown to be smaller than those that occurred with KTX trains; it means that the bridge girders are more controlled with increased trains speed [31].

In other way, the low frequency content (static frequency change) for the bridge girders is shown in Figure 13. From this figure, it can be seen that no dominant frequencies are shown in the two girders with KTX train, while, with HEMU train, it can be seen that the low frequency modes of the steel girder are clearly detected compared with the PSC girder. It means that the quasistatic deformation for the two girders is equal as confirmed before with model identification analysis in the time domain.

4.4. Bridge Behavior Assessment. It is known that once the fatigue crack appears, extensive fatigue cracking may occur and will cause severe consequences [7,32,33]. There are several factors that influence the fatigue life of the bridge such as the traffic and environmental changes and the degradation of structural components of the bridge [7, 32]. Therefore, the design fatigue life of a bridge component reflects the actual conditions of the bridge. To perform structural deterioration and fatigue damage evaluation, Follen et al. [33] have utilized a probability density function using real-time strain measurements. In addition, O’Brien [34] has summarized that the displacement measurements by LVDT sensors can be used to detect the fatigue of structures. However, in this section, we used the probability theory based on deflection measurements, collected by LVDT sensors, to assess the behavior of bridge under different trains speeds. The Weibull distribution is widely used in statistical analysis to evaluate the behavior of the collection data $[33,35]$. In failure analysis, it is used to represent the deflection probability density function, commonly referred to as the deflection distribution. The Weibull distribution function is given by [35]

$$
\begin{aligned}
p\left(d<d_{i}<d+\Delta d\right) \\
=p(d>0)\left(\frac{k}{c}\right)\left(\frac{d_{i}}{c}\right)^{k-1} \exp \left\{-\left(\frac{d_{i}}{c}\right)^{k}\right\} \Delta d,
\end{aligned}
$$

where $c$ is the Weibull scale parameter, with units equal to the displacement unit, $k$ is the unitless Weibull shape parameter, $d$ is displacement of bridge, $\Delta d$ is an incremental displacement, $p\left(d<d_{i}<d+\Delta d\right)$ is the probability that the deflection is between $d$ and $d+\Delta d$, and $p(d>0)$ is the probability that the deflection exceeds zero; however, in this
TABLE 4: Weibull parameters for the displacement measurements.

\begin{tabular}{lccc}
\hline Train & Parameters & PSC girder & Steel girder \\
\hline \multirow{2}{*}{ KTX } & $c$ & 0.116 & 0.251 \\
& $k$ & 0.581 & 0.516 \\
\multirow{2}{*}{ HEMU } & $c$ & 0.229 & 0.297 \\
& $k$ & 0.790 & 0.612 \\
\hline
\end{tabular}

case, the absolute displacement measurements are applied [33].

The $k$ parameter is one of the most important aspects of the failure studies [36-38]. Weibull $k$ parameter distributes to less than, equal to, or greater than one $[36,37]$. Weibull distribution with a parameter less than 1 has a failure rate that decreases with time and is known as early-life failure, while with a parameter more than 1 it has a failure rate that increases with time and is known as wear-out failure $[36,38]$. However, Weibull distribution with a parameter close or equal to 1 has a constant failure rate that indicates a random failure or a useful life time [36, 38]. Herein, the Weibull parameters are used to assess the behavior of bridge under KTX and HEMU trains, and the Graphic method $[35,39]$ is used to estimate the Weibull parameters. Table 4 illustrates the extracted parameters of bridge girders under the two trains' speeds. The parameters evaluation is presented in Figure 14(a); and the comparisons between the cumulative distributions functions (CDF) for the two girders with trains KTX and HEMU is presented in Figure 14(b).

Figure 14(a) presents a comparison between the CDF of the original data and CDF calculated based on Weibull distribution for the steel girder with HEMU train. The correlation coefficient is calculated between the two results for each case of loads for the two girders and it is shown that the correlation is 0.94 and 0.96 for the steel and PCS girders, respectively, with KTX train. In addition, the correlation is 0.96 and 0.93 for the steel and PSC girders, respectively, with HEMU train. Therefore, it can be concluded that the Weibull distribution can be used to assess the performance of displacement measurements. Moreover, from Figure 14(b), it can be seen that the probability distribution for the steel girder is approximately the same with different trains speeds, while it is vice versa for PSC girder. It means that the steel girder shows more stability than PSC girder under speed changes of trains.

From Table 4 and Figure 14(b), it can be seen that the $k$ values for the two girders with two loaded cases are less than one; it means that the failure rate is in an early-life failure. Moreover, it can be seen that the $k$ parameter for the steel girder is less than that calculated for the PSC girder. It indicates that the failure rate for the steel girder is less than that for PSC girder. In addition, it can be observed that the $k$ parameter value is increased when increasing the train velocity by 15.68 and $26.45 \%$ for the steel and PSC girders, respectively. That means the failure rate is increased when the train speed increases. Otherwise, the $c$ parameter is defined as the volume distribution of the measurements. From Table 4, it can be seen that the variance between the parameter value with PSC and steel girders is 0.113 


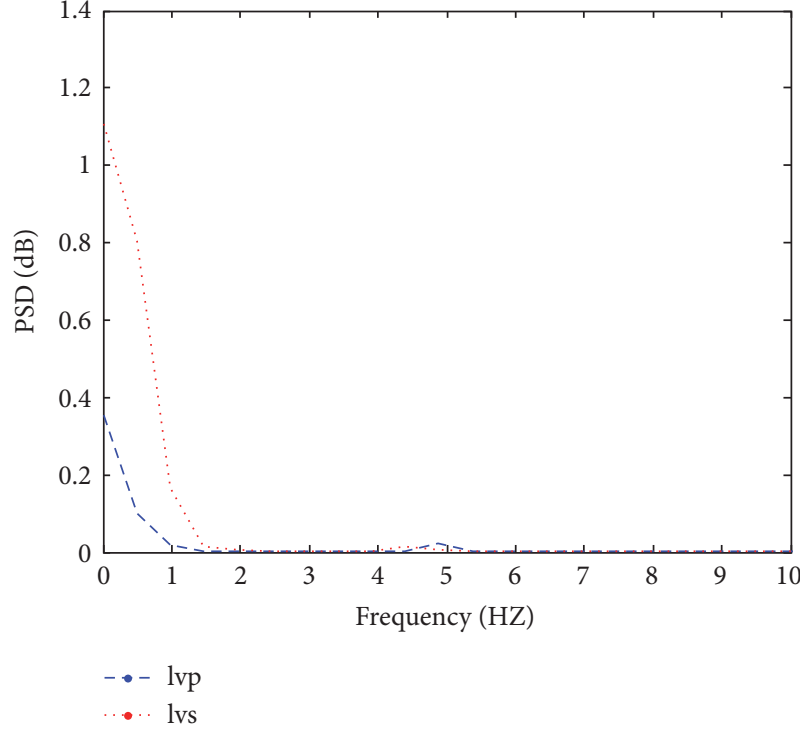

(a)

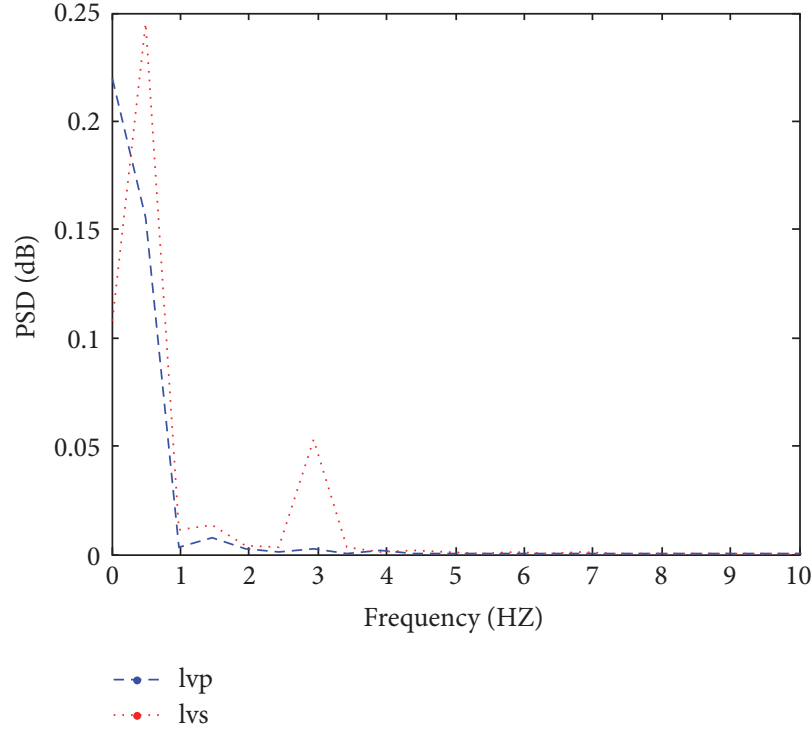

(b)

FIGURE 13: Displacement frequency contents for the (a) KTX and (b) HEMU.

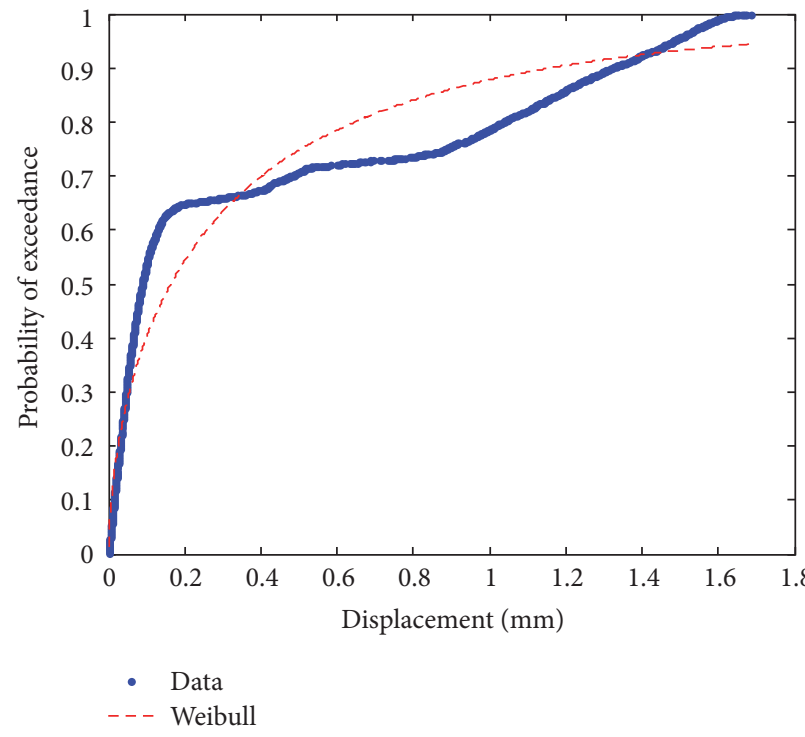

(a)

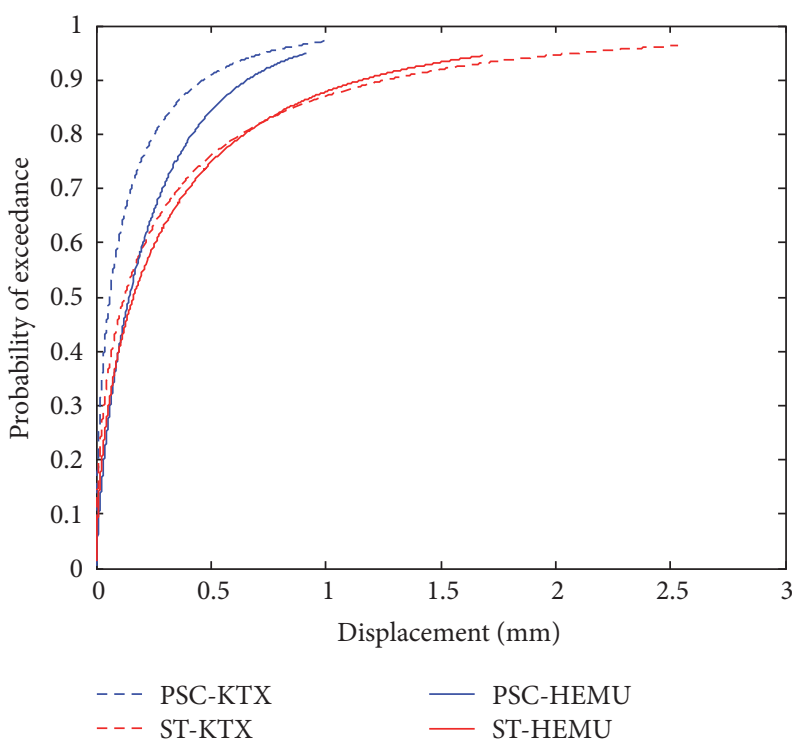

(b)

FIGURE 14: Cumulative distribution function (CDF) of the bridge girders displacement: (a) original data and Weibull calculation; (b) different girders displacement measurements.

and $0.046 \mathrm{~mm}$, respectively. It means that the distribution changes of displacement measurement for the PSC girder are greater than those for the steel girder.

\section{Summary and Conclusion}

This study investigates the performance of the Yonjung Bridge that is designed to transport high-speed trains (HEMU$430 \mathrm{X}$ ) with maximum operating speed of $430 \mathrm{~km} / \mathrm{h}$. The performance of the bridge is assessed in terms of analyzing the recorded deformations and accelerations in time and frequency domains. Two types of bridge girders are considered: prestressed reinforced concrete and composite steel box girders. These girders are investigated under different speeds of the passing train. Two various types of high-speed trains are used in this study: KTX and HEMU trains. The identification model parameters and the frequency contents are proposed and calculated.

The acceleration and quasistatic deformations of the PSC and steel girders decreased when considering higher train speeds. Furthermore, the difference between the maximum 
acceleration variations between passage and opposite direction for the PSC girder is shown to be higher than the variation for steel girder. The maximum deflection and acceleration were within the design criteria of the Korea Rail Network Authority.

The $\operatorname{ARMA}(0,1)-\operatorname{GARCH}(1,1)$ model parameters analyses and evaluation showed that the model design for the performance of structure totally depends on two parameters that are the measurements and the variance of measurements. In addition, the models for the steel girder with KTX or HEMU are better than the PSC girder in the two recorded measurement types. It indicated the rigidity of PSC girder that influenced the model identification quality of the bridge performance. The parameters change in case of the acceleration measurements were higher than the displacement measurements; this implied the difference of the acceleration response compared with the dynamic deformation under each train case and bridge. Moreover, the quasistatic deformations of the PSC and steel girders are approximately equal when considering low speeds, while the quasistatic and dynamic deformation of the two girders are different under high speeds.

The dominant frequency change for the PSC girder is significantly smaller than for the steel girder, which referred to the rigidity of PSC girder. Furthermore, the dynamic performance did not suffer major changes when increasing the train speed, while at low speeds the frequency content of the dynamic deformation considerably changed. Finally, no low frequency modes occurred with the KTX train, while low frequency modes were easily observed with HEMU train especially when considering the steel girder, which explained the convergence of the quasistatic (low frequency) deformations for the two girders.

Finally, the measurements assessment shows that the failure rate of the bridge is in an early-life failure stage, while the failure rate for the steel girder is observed to be less than that for PSC girder. Moreover, the steel girder is shown to be more stable than the PSC girder under the train speed change. Nevertheless, it can be concluded that the bridge is safe under the different high-speed trains.

\section{Competing Interests}

The authors declare that there is no conflict of interests regarding the publication of this paper.

\section{Acknowledgments}

This work was supported by a 2016 Incheon National University (INU) Research Grant. The authors gratefully acknowledge these supports.

\section{References}

[1] Midwest High Speed Rail Association, High-Speed Rail in Korea: Lessons for the Midwest, 2013.

[2] K. Man Cheol, C. Woo Jin, and K. Kee Dong, Performance Evaluation of KHSR Bridge Using Two-Dimensional
Train/Track/Bridge Interaction Analysis Method, Korea Railroad Research Institute, 2001.

[3] D. Van Naguyen, K. Du Kim, J. S. Shim, E. S. Choi, and S. Suthasupradit, "Development of three-dimensional dynamic analysis model high speed train-bridge interaction," Journal of Korean Society of Steel Construction, vol. 20, no. 1, pp. 151-163, 2008.

[4] S. I. Kim, J. Lee, and S. Kim, "Dynamic behavior comparison of steel-composite and concrete high speed railway bridges," International Journal of Steel Structures, vol. 11, no. 4, pp. 445455, 2011.

[5] B. Yan, G.-L. Dai, and N. Hu, "Recent development of design and construction of short span high-speed railway bridges in China," Engineering Structures, vol. 100, pp. 707-717, 2015.

[6] H. Yoon, W. J. Chin, J. Cho, J. Y. Kang, and J. Kwark, "Comparison of measured and dynamic analysis vertical accelerations of high-speed railway bridges crossed by KTX train," Engineering, vol. 5, no. 9, pp. 756-763, 2013.

[7] Y.-L. Ding, G.-X. Wang, P. Sun, L.-Y. Wu, and Q. Yue, "Longterm structural health monitoring system for a high-speed railway bridge structure," The Scientific World Journal, vol. 2015, Article ID 250562, 17 pages, 2015.

[8] Y.-L. Ding, P. Sun, G.-X. Wang et al., "Early-warning method of train running safety of a high-speed railway bridge based on transverse vibration monitoring," Shock and Vibration, vol. 2015, Article ID 518689, 9 pages, 2015.

[9] M. Kaloop, J. Hu, and E. Elbeltagi, "Evaluation of high-speed railway bridges based on a nondestructive monitoring system," Applied Sciences, vol. 6, no. 1, p. 24, 2016.

[10] X. W. Ye, Y. Q. Ni, K. Y. Wong, and J. M. Ko, "Statistical analysis of stress spectra for fatigue life assessment of steel bridges with structural health monitoring data," Engineering Structures, vol. 45, pp. 166-176, 2012.

[11] B. J. A. Costa and J. A. Figueiras, "Evaluation of a strain monitoring system for existing steel railway bridges," Journal of Constructional Steel Research, vol. 72, pp. 179-191, 2012.

[12] V. Alves, A. Meixedo, D. Ribeiro, R. Calçada, and A. Cury, "Evaluation of the performance of different damage indicators in railway bridges," Procedia Engineering, vol. 114, pp. 746-753, 2015.

[13] M. D. Martínez-Rodrigo, J. Lavado, and P. Museros, “Dynamic performance of existing high-speed railway bridges under resonant conditions retrofitted with fluid viscous dampers," Engineering Structures, vol. 32, no. 3, pp. 808-828, 2010.

[14] J. M. Rocha, A. A. Henriques, and R. Calçada, "Probabilistic safety assessment of a short span high-speed railway bridge," Engineering Structures, vol. 71, pp. 99-111, 2014.

[15] K. Eunsung, P. JongWoong, and S. SungHan, "Dynamic behavior of composite steel girder bridge exceeding train speed $350 \mathrm{~km} / \mathrm{h}$," Journal of the Korea Academia-Industrial cooperation Society, vol. 14, no. 7, pp. 3518-3527, 2013.

[16] Eurocode, "Eurocode 1: actions on structures-part 2: traffic loads on bridges," Eurocode 1, vol. 2, no. 2003, 2003.

[17] B. Jeon, N. Kim, and S. Kim, "Deflection limit based on vibration serviceability of railway bridges considering the correlation between train speed and vertical acceleration on coach," Journal of the Korean Society for Railway, vol. 14, no. 6, pp. 545-554, 2011.

[18] M. R. Kaloop and H. Li, "Multi input-single output models identification of tower bridge movements using GPS monitoring system," Measurement, vol. 47, no. 1, pp. 531-539, 2014. 
[19] H. Sohn, C. R. Farrar, F. Hemez, and J. Czarnecki, "A review of structural health monitoring literature 1996-2001," in Proceedings of the 3rd World Conference on Structural Control, pp. 1-7, December 2002.

[20] J.-H. Weng, C.-H. Loh, J. P. Lynch, K.-C. Lu, P.-Y. Lin, and Y. Wang, "Output-only modal identification of a cable-stayed bridge using wireless monitoring systems," Engineering Structures, vol. 30, no. 7, pp. 1820-1830, 2008.

[21] C. R. Farrar and K. Worden, "An introduction to structural health monitoring," Philosophical Transactions of the Royal Society A: Mathematical, Physical and Engineering Sciences, vol. 365, no. 1851, pp. 303-315, 2007.

[22] R. H. Shumway and D. S. Stoffer, Time Series Analysis and Its Applications with R Examples, 2011.

[23] M. R. Kaloop and J. W. Hu, "Stayed-cable bridge damage detection and localization based on accelerometer health monitoring measurements," Shock and Vibration, vol. 2015, Article ID 102680, 11 pages, 2015.

[24] S. Nagarajaiah and B. Basu, "Output only modal identification and structural damage detection using time frequency \& wavelet techniques," Earthquake Engineering and Engineering Vibration, vol. 8, no. 4, pp. 583-605, 2009.

[25] E. Reynders, G. Wursten, and G. de Roeck, "Output-only structural health monitoring in changing environmental conditions by means of nonlinear system identification," Structural Health Monitoring, vol. 13, no. 1, pp. 82-93, 2014.

[26] S. Attaway, Matlab, 2013.

[27] A. Ghalanos, "Introduction to the rugarch package. (Version 1.3-1)," 2015, https://goo.gl/1nsPNP.

[28] R. T. Baillie and T. Bollerslev, "Prediction in dynamic models with time-dependent conditional variances," Journal of Econometrics, vol. 52, no. 1-2, pp. 91-113, 1992.

[29] P. Górski, "Investigation of dynamic characteristics of tall industrial chimney based on GPS measurements using Random Decrement Method," Engineering Structures, vol. 83, pp. 30-49, 2015.

[30] R. Brincker, L. Zhang, and P. Andersen, "Modal identification of output-only systems using frequency domain decomposition," Smart Materials and Structures, vol. 10, no. 3, pp. 441-445, 2001.

[31] Y. Bigdeli and D. Kim, "Active control of 3-D irregular building by using energy based neuro-controller," Advances in Structural Engineering, vol. 17, no. 6, pp. 837-849, 2014.

[32] S. Alampalli and R. Lund, "Estimating fatigue life of bridge components using measured strains," Journal of Bridge Engineering, vol. 11, no. 6, pp. 725-736, 2006.

[33] C. W. Follen, M. Sanayei, B. R. Brenner, and R. M. Vogel, "Statistical bridge signatures," Journal of Bridge Engineering, vol. 19, no. 7, Article ID 04014022, 2014.

[34] T. K. O’Brien, Composite Materials: Fatigue and Fracture (Third Volume), ASTM International, West Conshohocken, Pa, USA, 1991.

[35] J. V. Seguro and T. W. Lambert, "Modern estimation of the parameters of the Weibull wind speed distribution for wind energy analysis," Journal of Wind Engineering and Industrial Aerodynamics, vol. 85, no. 1, pp. 75-84, 2000.

[36] http://www.weibull.com/hotwire/issuel4/relbasics14.htm.

[37] F. Scholz, "Weibull Reliability Analysis," Department of statistics, University of Washington, 1999, http://www.stat .washington.edu/fritz/Reports/weibullanalysis.pdf.

[38] E. M. Hernandez, "Statistical analysis of weigh-in motion data for bridge design in vermont," TRC Report 14-014, University of Vermont Transportation Research Center, 2014.
[39] S. A. Akdag and A. Dinler, "A new method to estimate Weibull parameters for wind energy applications," Energy Conversion and Management, vol. 50, no. 7, pp. 1761-1766, 2009. 


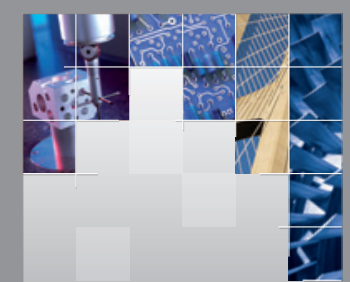

\section{Enfincering}
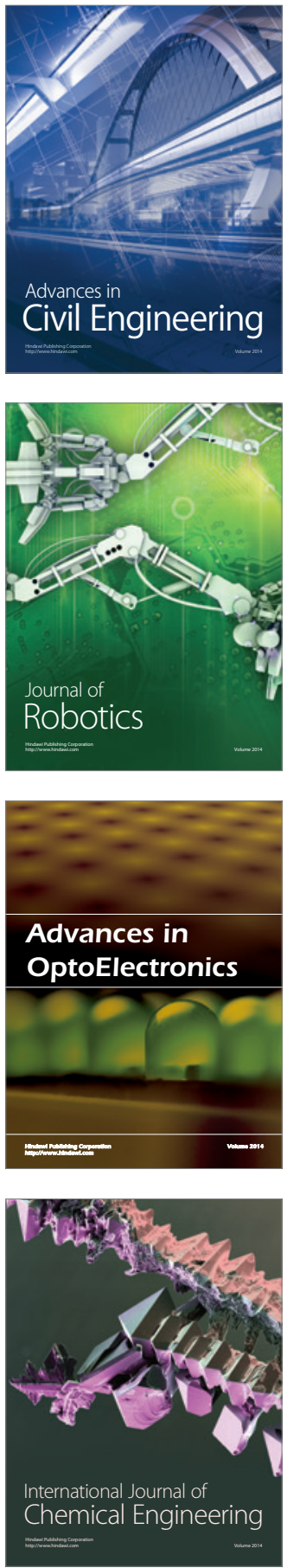

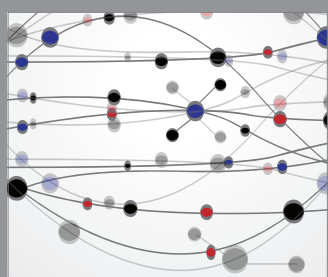

The Scientific World Journal

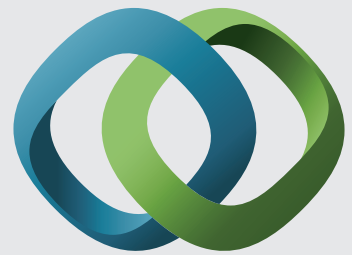

\section{Hindawi}

Submit your manuscripts at

http://www.hindawi.com
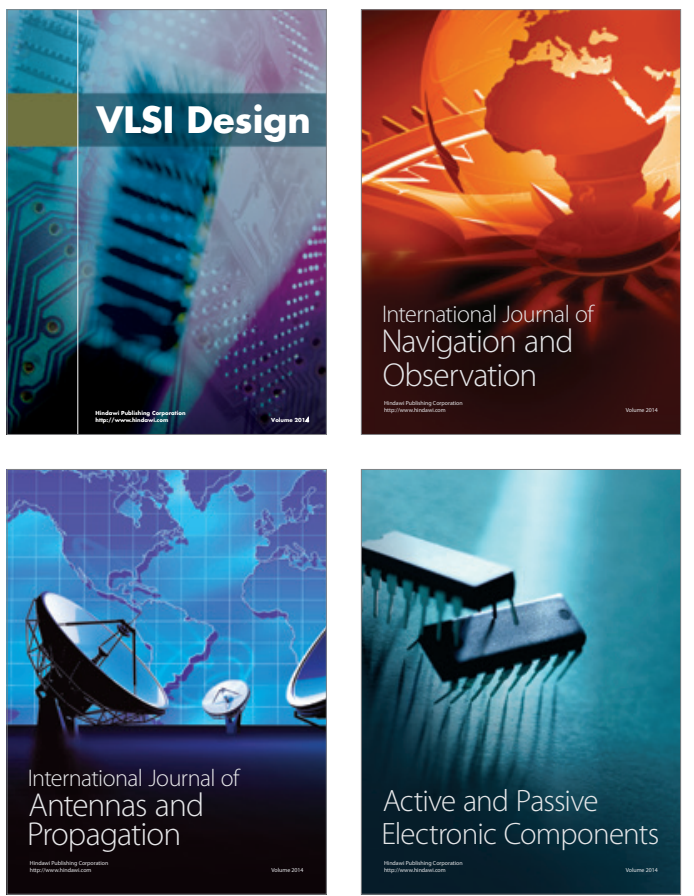
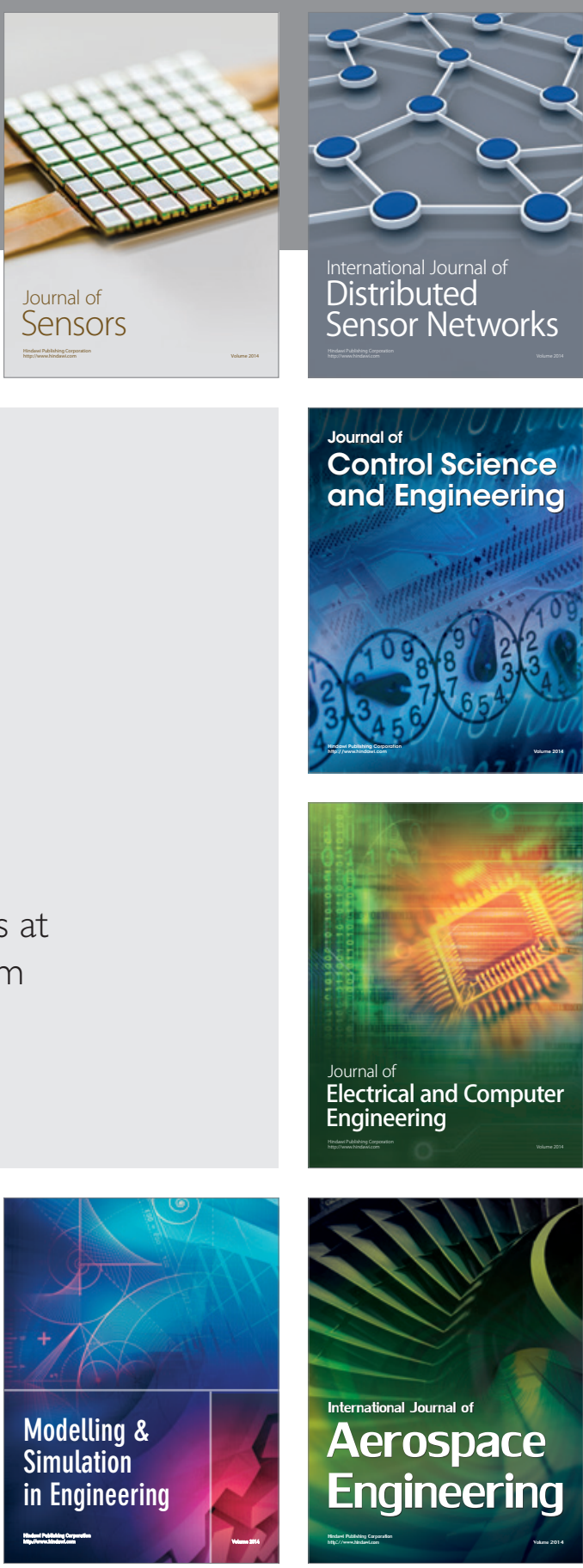

International Journal of

Distributed

Sensor Networks

Journal of

Control Science

and Engineering
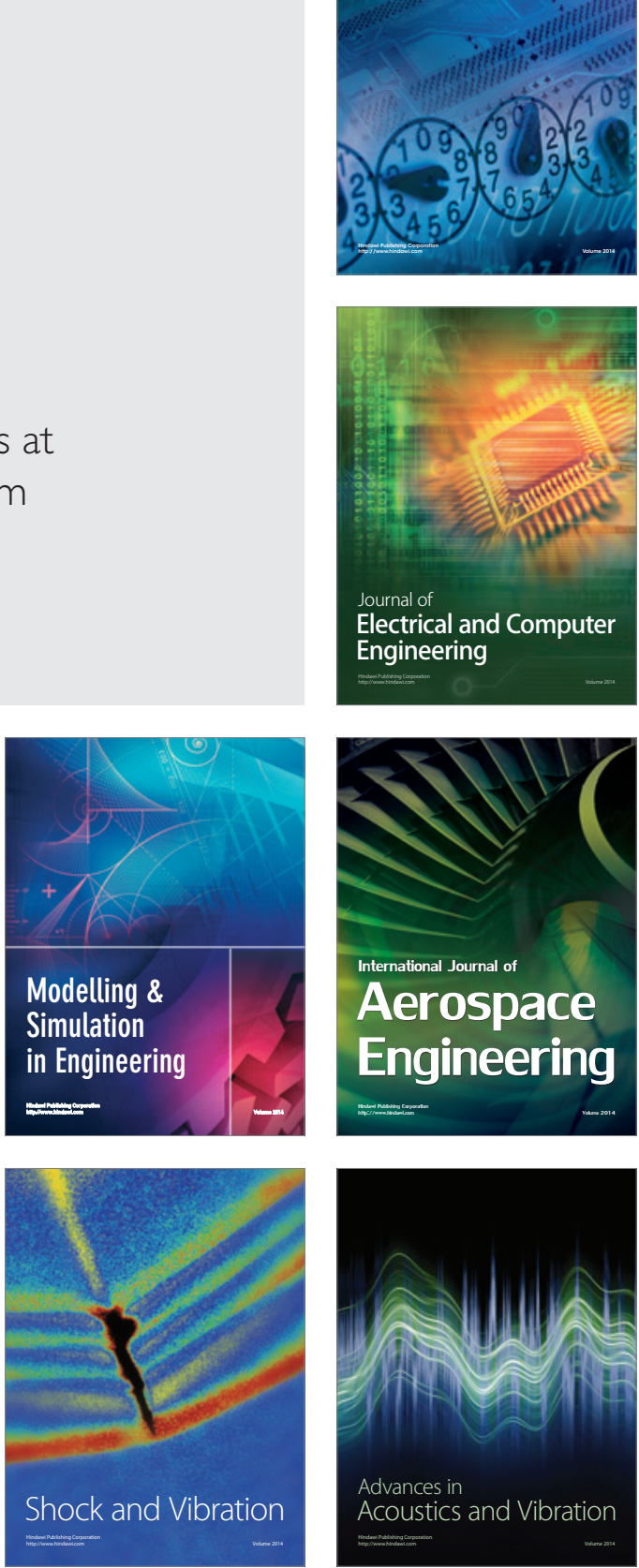